Open Access

\title{
Production of novel diagnostic radionuclides in small medical cyclotrons
}

\author{
Mateusz Adam Synowiecki ${ }^{1}$, Lars Rutger Perk ${ }^{1 *}$ and J. Frank W. Nijsen ${ }^{2}$
}

\author{
* Correspondence: lars.perk@ \\ radboudumc.nl \\ ${ }^{1}$ Radboudumc, Radboud \\ Translational Medicine B.V, Geert \\ Grooteplein 21 (route 142), 6525EZ \\ Nijmegen, The Netherlands \\ Full list of author information is \\ available at the end of the article
}

\begin{abstract}
The global network of cyclotrons has expanded rapidly over the last decade. The bulk of its industrial potential is composed of small medical cyclotrons with a proton energy below $20 \mathrm{MeV}$ for radionuclides production. This review focuses on the recent developments of novel medical radionuclides produced by cyclotrons in the energy range of $3 \mathrm{MeV}$ to $20 \mathrm{MeV}$. The production of the following medical radionuclides will be described based on available literature sources: Tc-99 m, I-123, I-124, Zr-89, Cu-64, Ga-67, Ga-68, In-111, Y-86 and Sc-44. Remarkable developments in the production process have been observed in only some cases. More research is needed to make novel radionuclide cyclotron production available for the medical industry.

Keywords: Radionuclide production, Cyclotron, Technetium-99 m, Radioiodine, Zirconium-89, Copper-64, Gallium-67, Gallium-68, Yttrium-86, Scandium-44
\end{abstract}

\section{Background}

High-purity radionuclides are a key element in the development of radiopharmaceuticals for applications in nuclear medicine. Radionuclides are used in diagnostic and therapeutic radiopharmaceuticals. Often, they can be imaged by Single Photon Emission Computed Tomography (SPECT) or Positron Emission Tomography (PET). Over the last few decades, research groups in both the private and public sector conducted numerous development studies of new radiotracers. This resulted in a constantly evolving radiopharmaceutical market trying to satisfy the needs of the medical society. Many failed introductions of new radiopharmaceuticals resulted from the inability to stand out from the products that are currently available. This is due to little added value or a lack of clinical relevance. Those that are successful in manifesting their benefits then face another barrier. Zimmermann et al. described that the road of successful new radiopharmaceuticals is paved with failures because of the many industrial and regulatory constraints (Zimmermann, 2013). The clinically used radionuclides should satisfy requirements such as:

- Physical properties suitable for its application (half-life $\left(\mathrm{T}_{1 / 2}\right)$, decay mode, emission energy);

- Chemical properties suitable for labeling, with high radiochemical yields and a high radionuclidic purity;

(C) The Author(s). 2018 Open Access This article is distributed under the terms of the Creative Commons Attribution 4.0 International License (http://creativecommons.org/licenses/by/4.0/), which permits unrestricted use, distribution, and reproduction in any medium, provided you give appropriate credit to the original author(s) and the source, provide a link to the Creative Commons license, and indicate if changes were made. 
- An acceptable trade-off between the dose received by the patient and the desired effect (image quality or treatment);

- A reasonable price range.

On the other hand, from a radiopharmaceutical industry point of view, a radionuclide selected for production must meet certain criteria to be of interest:

- The production efficiency is acceptable in terms of equipment and personnel burden;

- The starting materials are not too expensive; the supply is secured and remains stable in the long term;

- It offers a high molar activity;

- It is expected to be carrier-free or no-carrier added in order to limit the toxicity;

- Radionuclide production and the post-processing chemistry can be simplified, with a preference for automation (because of Good Manufacturing Practice (GMP), radiation safety and costs concerns);

- Its half-life is suitable for logistics;

- There is sufficient demand on the market.

It often happens that the above criteria from both sides are not met, which causes the radionuclide to never reach widespread application. In addition to that, other implications (such as political or economical changes) may discourage the production of certain radionuclides. This is typically the case when government allocated investments or decisions influence the distribution of sources of the radionuclide, e.g. by phasing out a nuclear reactor (Krijger et al., 2013). Currently most hospital radio-pharmacies derive their radionuclides from three types of sources: nuclear research reactors, radionuclide generators and cyclotron facilities (Table 1). It is worth mentioning that the generators still need a reactor or cyclotron source to produce the parent radionuclide. There are also other, much less common ways of producing radionuclides by using linear accelerators (Mang'era et al., 2015), Van De Graaf accelerators (Jones, Robinson Jr., and McIntyre, 1984) or lasers (Bychenkov, Brantov, and Mourou, 2014).

This review article focuses on recent developments in the production of novel diagnostic radionuclides by using small medical cyclotrons. Some of the presented radionuclides can potentially be used in theranostic applications, i.e. a combined diagnostic and therapeutic effect within single application of the radiopharmaceutical.

\section{Cyclotron produced radionuclides}

Classical cyclotron produced radionuclides are defined in this article as produced by very well-established technologies using mostly liquid or gas targets (Fig. 1). Typically, they are produced routinely on an almost daily basis and therefore present the bulk of targetry solutions offered by the cyclotron manufacturers. Among these classical radionuclides are: ${ }^{18} \mathrm{~F},{ }^{13} \mathrm{~N},{ }^{11} \mathrm{C}$ and ${ }^{15} \mathrm{O}$. These four PET radionuclides are also commonly referred to as "standard" radionuclides in literature and are mostly produced using low energy medical cyclotrons. ${ }^{123} \mathrm{I}$ and ${ }^{111} \mathrm{In}$ are two of the cyclotron produced radionuclides used in SPECT studies that can be regarded as classical. However, these are 
Table 1 Common types of radionuclide sources

\begin{tabular}{|c|c|c|c|}
\hline & Nuclear Reactors & Generators & Cyclotrons \\
\hline $\begin{array}{l}\text { Principle of } \\
\text { production }\end{array}$ & $\begin{array}{l}\text { Target material inserted in } \\
\text { the neutron flux field } \\
\text { undergoes fission or neutron } \\
\text { activation transmuting into } \\
\text { radionuclide of interest }\end{array}$ & $\begin{array}{l}\text { Long-lived parent radionuclide } \\
\text { decays to short-lived daughter } \\
\text { nuclide of interest. Daughter } \\
\text { nuclide elution follows in } \\
\text { pre-determined cycles }\end{array}$ & $\begin{array}{l}\text { Target material irradiation by } \\
\text { charged particle beams. } \\
\text { Inducing nuclear reactions } \\
\text { that transmute the material } \\
\text { into radionuclide of interest }\end{array}$ \\
\hline $\begin{array}{l}\text { Transmutation } \\
\text { base }\end{array}$ & Neutrons & Decay & $\begin{array}{l}\mathrm{p}, \mathrm{d}, \mathrm{t},{ }^{3} \mathrm{He}, \mathrm{a} \text { or heavy ion } \\
\text { beams }\end{array}$ \\
\hline Advantages & $\begin{array}{l}\text { - Production of neutron rich } \\
\text { radionuclides, mostly for } \\
\text { therapeutic use } \\
\text { - High production efficiency } \\
\text { - Centralized production: one } \\
\text { research reactor able to } \\
\text { supply to large regions or } \\
\text { in some cases globally }\end{array}$ & $\begin{array}{l}\text { - Available on site, no need } \\
\text { for logistics } \\
\text { - Mostly long shelf life } \\
\text { - Easy to use } \\
\text { - Limited radioactive waste: } \\
\text { returned to manufacturer } \\
\text { after use }\end{array}$ & $\begin{array}{l}\text { - Production of proton rich } \\
\text { elements used as } \beta^{+} \\
\text {emitters for PET scans } \\
\text { - Decentralized production } \\
\text { allows for back-up chains } \\
\text { - High uptime } \\
\text { - High specific activity in } \\
\text { most cases } \\
\text { - Small investment in } \\
\text { comparison to nuclear } \\
\text { reactor } \\
\text { - Little long-lived radioactive } \\
\text { waste }\end{array}$ \\
\hline Disadvantages & $\begin{array}{l}\text { - Extremely high investment } \\
\text { cost } \\
\text { - High operational costs } \\
\text { - Considerable amounts of } \\
\text { long-lived radioactive waste } \\
\text { - Long out-of-service periods } \\
\text { - Trouble to back-up in case } \\
\text { of unforeseen downtime } \\
\text { - Demanding logistics, often } \\
\text { involving air transport } \\
\text { - Public safety concerns } \\
\text { - Non-proliferation treaty } \\
\text { concerns }\end{array}$ & $\begin{array}{l}\text { - Supplies in cycles according } \\
\text { to possible elution frequency; } \\
\text { in-house use must be timed } \\
\text { accordingly } \\
\text { - Trace contaminants of } \\
\text { long-lived parent nuclide in } \\
\text { eluted product }\end{array}$ & $\begin{array}{l}\text { - Regional network of } \\
\text { cyclotrons and complex } \\
\text { logistics needed for } \\
\text { short-lived produced } \\
\text { radionuclides } \\
\text { - Radionuclide production } \\
\text { limited depending on } \\
\text { installed beam energy }\end{array}$ \\
\hline
\end{tabular}

produced by intermediate energy cyclotrons. The novel cyclotron produced radionuclides are defined as all others.

Production technology may already be well-established, like ${ }^{64} \mathrm{Cu}$ or ${ }^{124} \mathrm{I}$, but what makes them interesting is that they are mostly either produced on an irregular basis or in singular centers across a large area and that their clinical application is not yet established. Most of them are produced using solid target systems with some of them having a proven history of robustness, while others are still under development or require further optimization. Typically, novel radionuclides have relatively longer half-lives which allows for shipment to distant users. The following novel cyclotron produced radionuclides will be discussed (Fig. 1): ${ }^{99 \mathrm{~m}} \mathrm{Tc},{ }^{124} \mathrm{I},{ }^{89} \mathrm{Zr},{ }^{64} \mathrm{Cu},{ }^{67} \mathrm{Ga},{ }^{68} \mathrm{Ga},{ }^{86} \mathrm{Y},{ }^{44} \mathrm{Sc}$. Also, the classical radionuclides of ${ }^{123} \mathrm{I}$ and ${ }^{111} \mathrm{In}$ are discussed since there are possibilities to use small medical cyclotrons for their production.

\section{Types of cyclotrons}

Small medical cyclotrons (SMC) normally have a proton energy below $20 \mathrm{MeV}$ (Table 2). In the literature, they are referred to as medical cyclotrons, PET cyclotrons or small-sized cyclotrons. They offer proton beam currents typically in the range of 60-100 $\mu \mathrm{A}$. These accelerators are mostly installed in hospitals, universities and small-scale industrial radionuclide production plants. Many of these small medical cyclotrons have been installed 


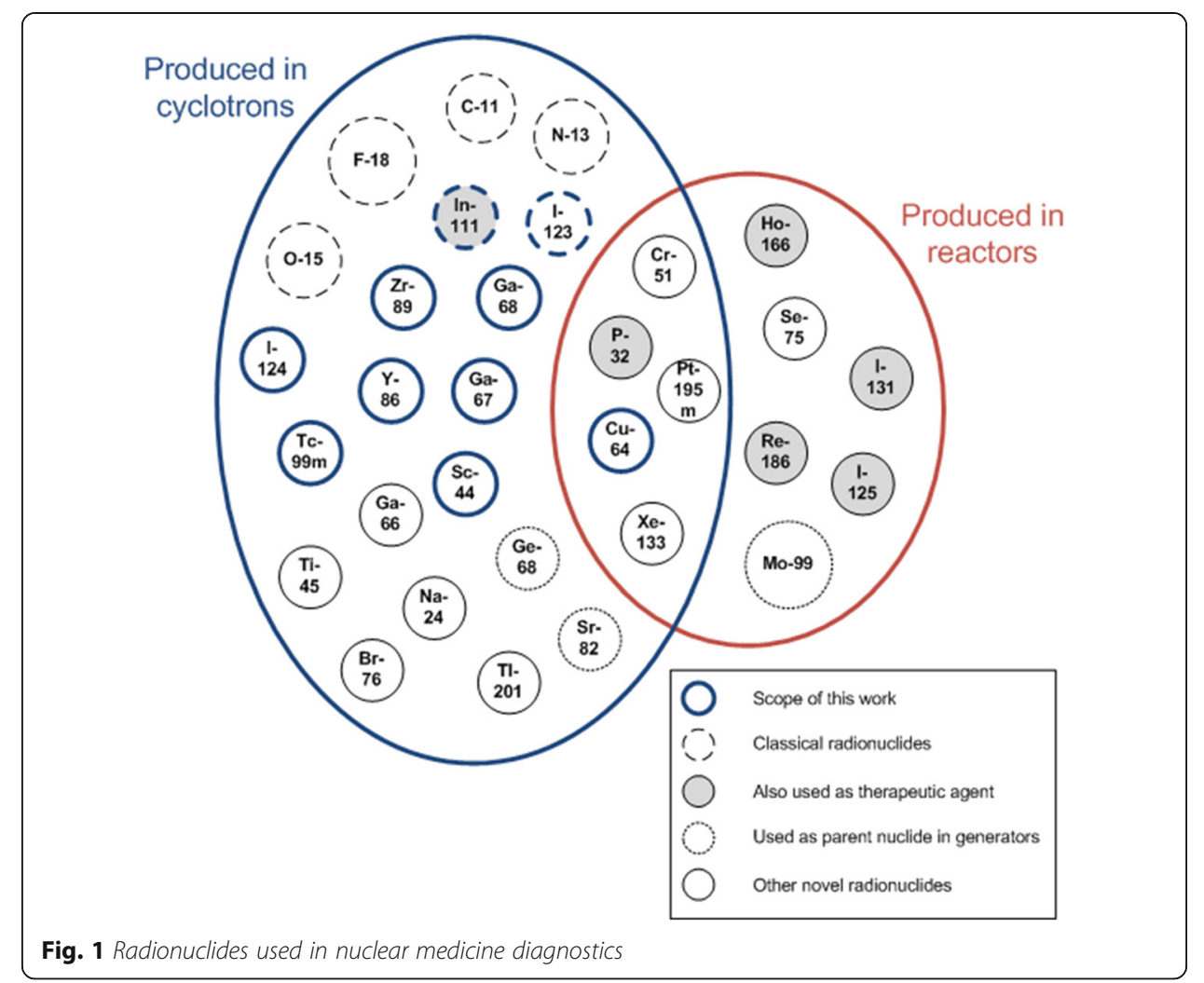

over the last two decades and the number is still increasing. In 2008, almost 700 cyclotrons were installed worldwide (IAEA, Cyclotron Produced Radionuclides: Principles and Practice, 2008). Only seven years later, according to Goethals et al. (Goethals and Zimmermann, 2015), that number has increased to 1218 cyclotrons whereof approximately 1000 are SMCs (Table 2). Most of the SMCs are located in the developed countries, although newly industrialized developing countries are rapidly increasing their cyclotron base. The majority of these SMCs have been manufactured by four companies in order of market share (Schaffer et al., 2015): General Electric Healthcare (GE Healthcare), Ion Beam Applications (IBA), Siemens and Advanced Cyclotron Systems Incorporated (ACSI). There are several other companies producing small or intermediate energy cyclotrons that are developing steadily (Schmor, 2010). Typically, SMCs accelerate protons only, with some of them also capable of accelerating deuterons at half of the specified energy of

Table 2 Distinction of cyclotron types (Goethals and Zimmermann, 2015)

\begin{tabular}{llll}
\hline Cyclotron type & Energy Range (MeV) & Approximate number & Typical location \\
\hline Small medical cyclotron (SMC) & $<20 \mathrm{MeV}$ & 1050 & $\begin{array}{l}\text { - hospitals } \\
\text { - universities }\end{array}$ \\
& & & - local commercial plants \\
Intermediate energy cyclotron & $20-35 \mathrm{MeV}$ & 100 & $\begin{array}{l}\text { - regional commercial } \\
\text { plants } \\
\text { - research institutes }\end{array}$ \\
& & & $\begin{array}{l}\text { - research institutes } \\
\text { High energy cyclotron }\end{array}$ \\
& $>35 \mathrm{MeV}$ & $50^{\text {a }}$ & cancer proton therapy \\
\hline
\end{tabular}


protons. Their purpose is the production of medical radionuclides for in-house use, research and commercial purposes. In general, they are focused on the production of short-lived standard radionuclides for PET studies.

Cyclotrons delivering protons of an energy between 20 and $35 \mathrm{MeV}$ are considered intermediate energy cyclotrons or medium cyclotrons. Besides the main proton beam capacity, they usually offer a deuteron beam, and few of them offer an $\alpha$ beam. These machines tend to be located at bigger radiopharmaceutical commercial plants or research institutes. Obviously, they can also be used to produce the classical PET radionuclides, but their main purpose is the production of classical SPECT and novel PET radionuclides, or parent nuclides for generators.

Cyclotrons of particle energies above $35 \mathrm{MeV}$ are considered high energy cyclotrons. They are scattered around the globe in well-regarded research institutes. These machines are tailored to specific research needs and can be designed to accelerate many kinds of particles: protons, deuterons, tritium, alpha and heavy ion beams. Many unique novel radionuclides can be produced, especially parent radionuclides for the generators, like ${ }^{68} \mathrm{Ge}$ or ${ }^{82} \mathrm{Sr}$. High energy cyclotrons are also installed in large clinical cancer centers for proton beam therapy.

\section{Cyclotron targetry}

The most important irradiation parameters determining the formation of a radioactive product are the beam flux, energy and irradiation time as well as number of target nuclei, nuclear reaction cross section and half-life of the produced radioisotope (Krijger et al., 2013; Qaim, 2017). Standard radionuclides are mostly produced in either gas or liquid targets. These targets are very easy to use and require no manual handling for routine production activities. The fluidic nature of the irradiated element makes rapid heat exchange possible. Provided water cooling has the potential to remove the heat produced by the intensity of the beam up to the maximum specification of the cyclotron. Often, helium cooling is used for the beam window, i.e. the target element through which the beam enters the isolated target material within the target body. Just after End of Bombardment (EOB), the unloading process is performed by pressurized inert gas that pushes the produced radioactivity through small bore tubing to the automatic synthesis module. Therefore, the gas and liquid target methods are safe, reliable and fast.

\section{Solid targets}

For novel radionuclides, solid targets are often used. Solid targets present a number of difficulties when compared with gas and liquid targets:

1. Often, expensive enriched target materials must be used to produce radionuclides with a high purity;

2. The heat conductivity is much lower, which can lead to overheating problems. Care must be taken to optimize the cooling system and beam parameters to avoid melting of the target. Usually, an inclined target design is proposed with an angle of a few degrees between the incident beam and material layer. This ensures that the entering beam power heat is dissipated over a bigger target area (Fig. 2); 


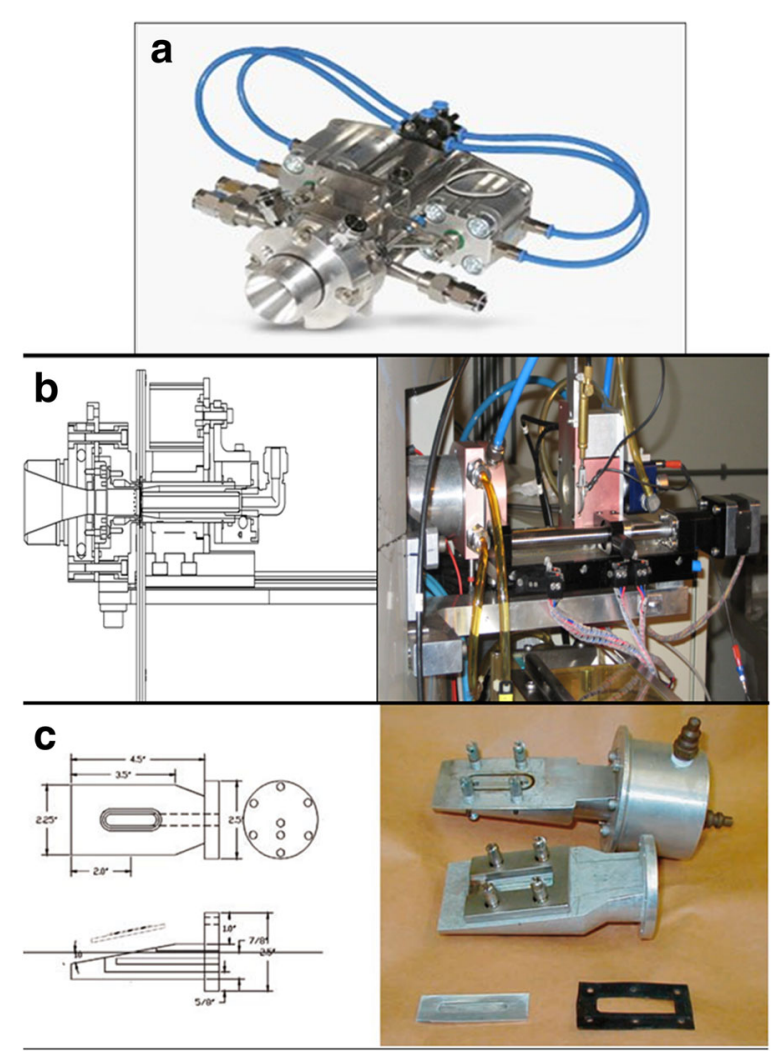

Fig. 2 Examples of solid targets. a COSTIS (Compact Solid Target Irradiation System) IBA Nirta target, b Custom developed Zirconium-89 target, images courtesy of Roel Mooij, BV Cyclotron VU, Amsterdam, NL c Custom developed inclined solid target, black line depicts beam direction from the cyclotron, cross section visualizes cooling channels (IAEA, Cyclotron Produced Radionuclides: Principles and Practice, 2008)

3. The target material layer should be a few hundred $\mu \mathrm{m}$ thick and placed on the back plate made of highly conductive metal. This process requires material deposited isotropically and in a pure form (or sometimes using various oxides). Typically, electrodeposition or powder pressing must be used, followed by sintering. Other methods include powder rolling, laser plating and forming high melting point alloy (Qaim Syed, 2011; Stolarz et al., 2015);

4. Solid state targets require more manual handling which causes a higher radiation hazard for personnel, especially when the target must be retrieved shortly after irradiation. Automation of the delivery line is possible with pneumatic systems;

5. Solid target material in general requires more complex chemical separation steps and further recycling steps.

To overcome overheating problems, low beam currents are used which results in low production yields. Therefore, the beam time is increased to reach useful amounts of radionuclides. Together with chemical and technical challenges, this makes the whole solid target production process time consuming, labor intensive, hazardous in terms of radiation safety and thus expensive.

Many of the solid targets for production of novel radionuclides had to be developed and optimized in-house, which resulted in various and incomparable performances and run parameters when collected between the centers. Design possibilities of those targets 
often encountered problems related to space limitation caused by cyclotron or target shielding, vault dimensions or technical installations. Nowadays, most cyclotron manufacturers have standardized compact solid target systems available for more popular novel radionuclides. These targets offer easier maintenance, have high automation capabilities and are supplied as a plug-and-play system.

Custom targets have the potential to reach higher yields in comparison to the standard off the shelf compact target (systems). To our opinion this is due to the goal of the custom target developers design their target to be better optimized for their specific conditions of usage and to maximize the yields. On the other hand cyclotron manufacturers with their compact targets, aside for maximizing yields, aim to assure high level of safety, easiness of handling for personnel and introducing more replaceable materials. This situation may create a "trade-off" dilemma for a radionuclide production plant operating a SMC which technology to decide on for a new solid targetry based production.

\section{Liquid targets for radiometals production}

A recent development in the production of radiometals involves the use of solution targets (i.e. liquid targets), where the target material is dissolved in an aqueous solution in the form of salts. This method removes the drawbacks that are mentioned for solid targets and offers the following advantages: simple handling, on-demand availability, a faster production process without dissolution and adjustable use of enriched material depending on the needs for a single production, which greatly reduces the cost (Alves et al., 2017). However, the production of radiometals using liquid targets comes with a number of disadvantages, most noticeable the significantly lower production yields. To optimize these methods, certain problems need to be addressed before large-scale implementation.

One of them is the target pressure build-up during irradiation. This effect depends on the beam intensity and concentration of the target material. The irradiation of aqueous solutions leads to water radiolysis and the creation of ions and free radicals of hydrogen, oxygen and hydroxyl groups, which in turn leads to rapid gas evolution in the target chamber $\left(\mathrm{H}_{2}\right.$ and $\left.\mathrm{O}_{2}\right)$. This effect is further promoted by the introduction of certain types of salt cations and anions. Those effects were studied and minimized in a recently published patent invented by DeGrado et al. (DeGrado, Pandey, and Byrne, 2017). In particular cases, the introduction of strong nitric acid proves to minimize the gas evolution in the target because the nitric acid acts as a free radical scavenger. Another solution is the introduction of a backpressure regulator which keeps the in-target pressure at a stable level during irradiation.

The authors also point out the importance of carefully selecting salt constituents as certain pairs of metallic cations and acidic anions affect the gas evolution in different ways. Additionally, strong acids used in targetry may result in corrosion of the targets. Other experiments using silver or aluminum targets demonstrated the presence of fine particles, leading to clogging of the transfer lines (Hoehr et al., 2012) and thus requiring frequent target maintenance. It is recommended to use heat-resistant and chemically inert materials (such as niobium and tantalum) as target materials. Optimization of target material, metallic salt composition and concentration of acid are all needed to prevent the formation of precipitates. Favorably, the addition of nitric acid also eliminates the precipitation of salts within target (DeGrado et al., 2017). 
Pandey et al. show high ratios (approximately $85-90 \%$ ) of enriched material recycling for liquid targets (Pandey et al., 2014a), which is a highly desirable and financially advantageous factor for considering the use of solution targets.

In general, the liquid target radiometal production technology is not yet mature and requires more studies to optimize production yields. For small facilities and/or facilities at remote locations, the recent liquid target developments allow for in-house production of radionuclides with small, shelf-shielded cyclotrons.

\section{Developments in radionuclide production}

Below, the current status and recent developments in the production of a number of novel radionuclides will be presented.

\section{Technetium-99m}

Technetium-99m ( $\left.{ }^{99 \mathrm{~m}} \mathrm{Tc}\right)$ is still undeniably the most commonly used radionuclide in the world. Its share in all nuclear medicine procedures is approximately $80 \%$, with an estimated 40 million patient preparations per year worldwide (OECD-NEA, 2017). Until recently, almost all of the ${ }^{99 \mathrm{~m}} \mathrm{Tc}$ used in nuclear medicine was produced by radioactive decay of ${ }^{99} \mathrm{Mo}$ confined in a generator. ${ }^{99 \mathrm{~m}} \mathrm{Tc}$ success in the clinic is based on advantageous physical properties such as: a moderate half-life $\left(\mathrm{T}_{1 / 2}=6.0 \mathrm{~h}\right)$, and low energy $99 \% \gamma$ emission of single peak of $140.5 \mathrm{keV}$. Moreover, other beneficial factors for its widespread use are: a low price, availability, and the fact that it is a generator product. Its parent radionuclide, ${ }^{99} \mathrm{Mo}$, is dominantly produced by a nuclear fission process of ${ }^{235} \mathrm{U}(\mathrm{n}, \mathrm{f})^{99}$ Mo in a few aging high neutron flux nuclear reactors running on Highly Enriched Uranium (HEU). The threat of possible shortages in the near future due to imminent closure of those facilities encouraged many research groups to investigate alternative methods for the production of ${ }^{99 \mathrm{~m}} \mathrm{Tc}$ without the use of a nuclear reactor (Table 3). Such studies are supported by the International Atomic Energy Agency (IAEA) through the project: "Accelerator based Alternatives to Non-HEU production of Mo-99/Tc-99m" (Accelerator-based Alternatives to Non-HEU production of Mo-99/Tc-99m, 2011).

The concept of producing sufficient amounts of ${ }^{99 \mathrm{~m}} \mathrm{Tc}$ from enriched ${ }^{100}$ Mo targets using a cyclotron was known from the early 70's (Beaver and Hupf, 1971). It was not developed further, since the current capacity of fission produced ${ }^{99} \mathrm{Mo}$ for usage in handy ${ }^{99} \mathrm{Mo} /{ }^{99 \mathrm{~m}} \mathrm{Tc}$ generators was sufficient for years to come. In addition, the nuclear reactor network was still expanding. In the 90's, several researchers again started the investigation of the nuclear data for proton induced reactions for molybdenum radionuclides, most notably ${ }^{100} \mathrm{Mo}(\mathrm{p}, 2 \mathrm{n}){ }^{99 \mathrm{~m}} \mathrm{Tc}$. The results renewed interest in the production of ${ }^{99 \mathrm{~m}} \mathrm{Tc}$ using cyclotrons and set the optimum production energy using protons in the range of 13.5-17 MeV, with a recommendation to avoid higher energies resulting in the production of inseparable impurities such as ${ }^{98} \mathrm{Tc},{ }^{97} \mathrm{Tc}$ and ${ }^{96} \mathrm{Tc}$ (Manenti et al., 2014; Qaim et al., 2014; Takacs et al., 2016).

Target design became the next milestone for successful cyclotron production of ${ }^{99 \mathrm{~m}} \mathrm{Tc}$, resulting in thick molybdenum coatings for solid targets able to withstand prolonged irradiation of high beam currents accompanied by an easy recovery of ${ }^{99 \mathrm{~m}} \mathrm{Tc}$ and recycling of ${ }^{100} \mathrm{Mo}$ after end of beam (Stolarz et al., 2015; Hanemaayer et al., 2014). 
The worldwide leading group for the targetry, beam optimization and ion source studies are undoubtedly Canadian researchers gathered under the auspices of the TRIUMF centre (Schaffer et al., 2015; Hanemaayer et al., 2014; Buckley, 2013; Benard et al., 2014). For the production of technetium-99m, they used solid targets of enriched molybdenum-100 coatings which resulted in a production yield of up to approximately $513 \mathrm{MBq} / \mu \mathrm{Ah}$. This can lead to $350 \mathrm{GBq}$ of ${ }^{99 \mathrm{~m}} \mathrm{Tc}$ on an ACSI TR-19 cyclotron $(6.9 \mathrm{~h}$ beam time, $300 \mu \mathrm{A}$ beam, cyclotron beam energy lowered to $18 \mathrm{MeV}$ protons) and about $170 \mathrm{GBq}$ on GE PETtrace 880 ( $6 \mathrm{~h}$ beam, modified to $130 \mu \mathrm{A}, 16.5 \mathrm{MeV}$ protons). In the case of $18 \mathrm{MeV}$ proton energy irradiations, which are slightly above the recommended energy range for ${ }^{99 \mathrm{~m}} \mathrm{Tc}$ production, the target contained approximately $95 \%$ of ${ }^{99 \mathrm{~m}} \mathrm{Tc}$ with $99.5 \%$ radionuclidic purity at EOB. The separation efficiency of ${ }^{99 \mathrm{~m}} \mathrm{Tc}$ from a molybdenum target, which can be easily automated, was proved to be in the range of $80 \%-90 \%$. With the radiochemical purity of $99.7 \%$ of the final pertechnate $\left[{ }^{99 \mathrm{~m}} \mathrm{Tc}\right] \mathrm{TcO}_{4}$ solution, the same USP quality requirements $(>95 \%)$ as for ${ }^{99} \mathrm{Mo} /$ ${ }^{99 \mathrm{~m}} \mathrm{Tc}$ generator produced pertechnate are met. The final efficiency of ${ }^{100} \mathrm{Mo}$ recycling is above $90 \%$. Other research groups have produced data on similar experiments that concur with these results (Das et al., 2016; Rovais et al., 2016).

Such capacity can fulfill a daily demand for a large area, thus encouraging the Canadian government to co-finance and support The Canadian National Cyclotron Network project, run by ACSI, which will cover $100 \%$ of Canadian needs for ${ }^{99 \mathrm{~m}} \mathrm{Tc}$ (ACSI, n.d.). The project was scheduled to be finalized before closure of the Chalk River nuclear reactor, once one of the leading suppliers of ${ }^{99} \mathrm{Mo}$, now operating as a back-up plant until its planned closure in March 2018. The project is ongoing, facing several delays caused by regulatory approval issues and logistics considerations (Brown, 2016), but some Canadian nuclear medicine patients are already scanned with cyclotron produced ${ }^{99 \mathrm{~m}} \mathrm{Tc}$.

An interesting alternative pathway of cyclotron production of ${ }^{99}$ Mo has been theoretically examined by a group from the Italian National Institute for Nuclear Physics (Pupillo et al., 2015). They use an $\alpha$-beam on an enriched Zirconium-96 target, thus inducing a ${ }^{96} \mathrm{Zr}(\alpha, \mathrm{n}){ }^{99} \mathrm{Mo}$ nuclear reaction. The above pathway does not produce sufficient amounts of ${ }^{99} \mathrm{Mo}$ for commercial use. However, it has the advantage of an extremely high specific activity in the range of $10^{6} \mathrm{TBq} / \mathrm{g}$ (current large generators have a specific activity of up to $370 \mathrm{TBq} / \mathrm{g}$ ). A limiting factor for the development of this pathway is the unavailability of high current $\alpha$ beams.

Alternative methods can utilize linear accelerators or lasers. The production of molybdenum-99 by utilizing electron induced brehmsstrahlung photons produced in linear accelerators is of particular interest. These targets require the same molydbenum-100 enriched material, but the nuclear reaction pathway is ${ }^{100} \mathrm{Mo}$ $(\gamma, n)^{99}$ Mo. Recent experiments in this field confirmed that this production pathway is feasible (Mang'era et al., 2015) and a steady supply of ${ }^{99} \mathrm{Mo}$ is expected to be provided soon by the already commissioned $35 \mathrm{MeV}, 40 \mathrm{~kW}$ Linear Accelerator (LINAC) at the Canadian Light Source. Similar projects based on the same principle are under development or consideration in other countries. NorthStar Medical Radionuclides, USA, is currently finalizing the ${ }^{99}$ Mo production method from the neutron capture ${ }^{98} \mathrm{Mo}(\mathrm{n}$,r) ${ }^{99}$ Mo using an old nuclear reactor at the University of Missouri Research Reactor Center (MURR). The company plans to expand its capacity by building a single site LINAC farm, comprised of up to 16 LINACs capable of producing ${ }^{99} \mathrm{Mo}$ by a 
photonuclear reaction on enriched ${ }^{100}$ Mo targets. The project is estimated to cover half of the USA demand for ${ }^{99 \mathrm{~m}} \mathrm{Tc}$ (NorthStar Medical Radioisotopes Receives $\$ 11.75$ Million from National Nuclear Security Administration, 2015; Harvey, Isensee, Moffatt, and Messina, 2014). The Lighthouse Consortium, Netherlands, is gathering companies and research institutes under the leadership of ASML, to achieve their goal of building an electron accelerator facility for ${ }^{99}$ Mo production from enriched ${ }^{100} \mathrm{Mo}$ targets. It is assumed that by 2021 the facility will be able to cover the capacity of the HFR nuclear reactor in Petten (Lighthouse: productie medische isotopen vanaf 2021, 2017). In Japan, considerations on which technology to rely on for securing the future ${ }^{99 \mathrm{~m}} \mathrm{Tc}$ supply are ongoing. The country already has a greatly developed particle accelerator infrastructure, allowing to diversify between production from linear accelerators, a vast cyclotron network of appropriate energies or even by using the Japan Proton Accelerator Research Complex (J-PARC) spallation facility (Nakai et al., 2014; Fujiwara et al., 2017).

Another alternative is the use of direct laser light that generates proton or electron fluxes further impinging on final targets. The disadvantage of this method is that the particle fluxes are not mono-energetic, which complicates yield calculations for side products. For this reason, a laser facility would require careful optimization of the laser target-nuclear target setup as a whole, to obtain a minimum number of co-produced impurities. Theoretical work in this field has been done with promising results (Bychenkov et al., 2014), yielding $300 \mathrm{GBq}$ of ${ }^{99 \mathrm{~m}} \mathrm{Tc}$ with $0.12 \%$ radionuclidic impurities in a $6 \mathrm{~h}$ irradiation assuming the utilization of the future International Coherent Amplification Network (ICAN) laser concept. However, in comparison to earlier mentioned advancements of particle accelerators, current laser-based ${ }^{99 \mathrm{~m}} \mathrm{Tc}$ production research and infrastructure is not developed enough for short-term considerations.

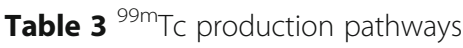

\begin{tabular}{|c|c|c|c|}
\hline Reaction & Method & $\begin{array}{l}\text { Currently } \\
\text { available }\end{array}$ & $\begin{array}{l}\text { Status and further } \\
\text { development }\end{array}$ \\
\hline${ }^{235} \mathrm{U}(\mathrm{n}, \mathrm{f})^{99} \mathrm{Mo} \rightarrow{ }^{99 \mathrm{~m}} \mathrm{Tc}$ & Reactor + generator & Worldwide & $\begin{array}{l}\text { Well-established, availability } \\
\text { will shrink with phasing out } \\
\text { of nuclear research reactors }\end{array}$ \\
\hline${ }^{100} \mathrm{Mo}(\mathrm{p}, 2 \mathrm{n}){ }^{99 \mathrm{~m}} \mathrm{Tc}$ & $\begin{array}{l}\text { Small medical or intermediate } \\
\text { energy cyclotron }\end{array}$ & In Canada & $\begin{array}{l}\text { Possible worldwide } \\
\text { implementation with } \\
\text { decreasing nuclear reactor } \\
\text { capacity }\end{array}$ \\
\hline${ }^{96} \mathrm{Zr}(\mathrm{a}, \mathrm{n}){ }^{99} \mathrm{Mo} \rightarrow{ }^{99 \mathrm{~m}} \mathrm{Tc}$ & a beam cyclotron + generator & No & $\begin{array}{l}\text { Will not be implemented. } \\
\text { Method not competitive, } \\
\text { a-beam required, low yields }\end{array}$ \\
\hline${ }^{100} \mathrm{Mo}(\gamma, n)^{99} \mathrm{Mo} \rightarrow{ }^{99 \mathrm{~m}} \mathrm{Tc}$ & LINAC+ generator & No & $\begin{array}{l}\text { Under development in } \\
\text { Canada, USA and the } \\
\text { Netherlands }\end{array}$ \\
\hline${ }^{98} \mathrm{Mo}(\mathrm{n}, \mathrm{\gamma}){ }^{99} \mathrm{Mo} \rightarrow{ }^{99 \mathrm{~m}} \mathrm{Tc}$ & Reactor + generator & $\begin{array}{l}\text { In USA and } \\
\text { Japan }\end{array}$ & $\begin{array}{l}\text { Auxiliary method used in } \\
\text { nuclear reactors } \\
\text { (Blaauw et al., 2017; van } \\
\text { der Marck, Koning, and } \\
\text { Charlton, 2010). Availability } \\
\text { will shrink with phasing } \\
\text { out of nuclear research } \\
\text { reactors }\end{array}$ \\
\hline${ }^{100} \mathrm{Mo}(\mathrm{p}, 2 \mathrm{n})^{99 \mathrm{~m}} \mathrm{Tc}$ & Laser & No & $\begin{array}{l}\text { Theoretically feasible. } \\
\text { Further research } \\
\text { required }\end{array}$ \\
\hline
\end{tabular}




\section{Radioiodines I-123, I-124}

Radioiodines have a long history of usage with changes in favoring different radionuclides throughout the last century (Silberstein, 2012). Today, the widely used ${ }^{131} \mathrm{I}$ therapeutic agent $\left(\mathrm{T}_{1 / 2}=8.02 \mathrm{~d}, 100 \% \beta^{-}, 90 \% \beta_{\mathrm{av}}^{-} 192 \mathrm{keV}, 82 \% \gamma 364 \mathrm{keV}\right)$ is produced in nuclear reactors. ${ }^{131} \mathrm{I}$ is also used for SPECT imaging thanks to its low energy gamma emission.

Iodine-123 is the second most widely used radioiodine and also the second most used imaging agent after ${ }^{99 \mathrm{~m}}$ Tc. Its popularity comes from its availability, perfect $\gamma$ energy for imaging and appropriate half-life for metabolic studies (Park, 2002). ${ }^{123} \mathrm{I}\left(\mathrm{T}_{1 / 2}=\right.$ $13.2 \mathrm{~h}, 100 \% \mathrm{EC}, 83 \% \gamma 158 \mathrm{keV})$ and ${ }^{124} \mathrm{I}\left(\mathrm{T}_{1 / 2}=4.18 \mathrm{~d}, 100 \% \mathrm{EC}^{+} \beta^{+}, 12 \% \beta_{\mathrm{av}}^{+} 687 \mathrm{keV}\right.$,

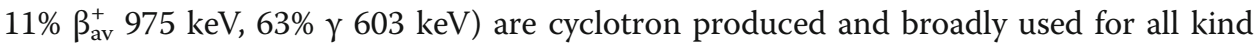
of applications (Silberstein, 2012; Koehler et al., 2010). ${ }^{123} \mathrm{I}$ is considered a classical radionuclide because of its widespread availability, well-established production method and routine production. Yet it remains an expensive endeavor since the production route utilizes proton irradiations of enriched xenon-124 gas $(50,000 \$ / 1$ as of 2008 (Kakavand et al., 2008)) in closed systems. This method employs two parallel nuclear reactions pathways and the following decay to ${ }^{123} \mathrm{I}:{ }^{124} \mathrm{Xe}(\mathrm{p}, 2 \mathrm{n}){ }^{123} \mathrm{Cs} \rightarrow{ }^{123} \mathrm{Xe} \rightarrow{ }^{123} \mathrm{I}$ and ${ }^{124} \mathrm{Xe}(\mathrm{p}, \mathrm{pn}){ }^{123} \mathrm{Xe} \rightarrow{ }^{123} \mathrm{I}$. It also requires an incident proton energy range between 20 and $30 \mathrm{MeV}$, which applies to a much smaller group of intermediate energy range cyclotrons. Such a produced final ${ }^{123}$ I radionuclide has an excellent radionuclidic purity of $99.9 \%$. It is included in this review due to the availability of an alternative production pathway using enriched Tellurium targets (see later in this section).

Iodine-124 has seen its rise in the first decade of the twenty-first century. Although having a disadvantage of a high energy prompt $\gamma$ which results in a high patient radiation dose and complicated dose calculations. It emits $\beta^{+}$, thus this isotope of iodine is fit for PET scans (Silberstein, 2012). Additional Auger electron emission gives it the capability to be named a theranostic agent. Iodine-124 production data is vast since many alternative nuclear production pathways exist, encompassing a big range of reactions based on: ${ }^{123-126} \mathrm{Te}(\mathrm{p}, \mathrm{xn}){ }^{124} \mathrm{I}$, ${ }^{123,124} \mathrm{Te}(\mathrm{d}, \mathrm{xn}){ }^{124} \mathrm{I},{ }^{121,123} \mathrm{Sb}(\alpha, \mathrm{xn}){ }^{124} \mathrm{I}$ and ${ }^{123} \mathrm{Sb}\left({ }^{3} \mathrm{He}, 2 \mathrm{n}\right){ }^{124} \mathrm{I}$ nuclear reactions. This irradiation data has been extensively evaluated (Koehler et al., 2010; Braghirolli et al., 2014; Azizakram et al., 2016; Aslam et al., 2010), with the result being an agreement found on the best approach to produce ${ }^{124} \mathrm{I}$ by means of an ${ }^{124} \mathrm{Te}(\mathrm{p}, \mathrm{n}){ }^{124} \mathrm{I}$ reaction in the range of $14-7 \mathrm{MeV}$ proton energy, with a yield reaching $21 \mathrm{MBq} / \mu \mathrm{Ah}$ and minimum ${ }^{125} \mathrm{I}$ impurities.

Both ${ }^{123} \mathrm{I}$ and ${ }^{124} \mathrm{I}$ have the great advantage of proton reaction cross section having a nuclear threshold below $10 \mathrm{MeV}$ on Tellurium targets (Soppera, Bossant, and Cabellos, 2017a). This gives the possibility to produce them with most cyclotrons. The developments in the last 20 years focused on the design of more efficient solid target systems (Kakavand et al., 2008; Mahunka et al., 1996; Al-Yanbawi and Al Jammaz, 2007; Nagatsu et al., 2011; Qaim et al., 2003; Poniger et al., 2012). $\mathrm{TeO}_{2}$ based thin layer targets can be used for the production of both iodines using the same target, by changing only the tellurium target isotope to match the reactions ${ }^{123} \mathrm{Te}(\mathrm{p}, \mathrm{n}){ }^{123} \mathrm{I}$ or ${ }^{124} \mathrm{Te}(\mathrm{p}, \mathrm{n}){ }^{124}$. The use of ${ }^{123} \mathrm{I}$ and ${ }^{124}$ I remains limited because the raw material cost of enriched tellurium (recyclable) remains high: \$10-50/mg (Fonslet and Koziorowski, 2013) which translates directly to the radionuclide price. 


\section{Zirconium-89}

Zirconium-89 $\left(\mathrm{T}_{1 / 2}=78.4 \mathrm{~h}, 100 \% \mathrm{EC}^{+} \beta^{+}, 23 \% \beta_{\mathrm{av}}^{+} 396 \mathrm{keV}, 99 \% \gamma 909 \mathrm{keV}\right)$ has been proven very useful in drug development, for instance for new antibody therapies. This is because of its:

1) long half-life that is suitable for studying the biodistribution of long-circulating proteins and antibodies,

2) reproducible applicability in chelating chemistry and conjugation with monoclonal antibodies (mAbs) used in ImmunoPET studies (Vosjan et al., 2010; Ikotun and Lapi, 2011; Rice et al., 2011),

3) balanced physical properties, i.e. sufficiently small $\beta^{+}$energy to maintain good image resolution and acceptable patient dose levels.

Zirconium-89 was associated with a low radionuclidic purity of the recovered product from Yttrium-89 target material and chelation chemistry (Holland, Sheh, and Lewis, 2009). The research group of the Vrije Universiteit (VU) University Medical Center in Amsterdam (NL) simplified the method which resulted in reproducible radiolabeling encouraging the worldwide development of the production and use of ${ }^{89} \mathrm{Zr}$ (Vosjan et al., 2010).

${ }^{89} \mathrm{Zr}$ can be produced in cyclotrons by 3 nuclear reaction pathways:

1) ${ }^{\text {nat }} \mathrm{Sr}(\alpha, \mathrm{xn})^{89} \mathrm{Zr}$

2) ${ }^{89} \mathrm{Y}(\mathrm{d}, 2 \mathrm{n}){ }^{89} \mathrm{Zr}$

3) ${ }^{89} \mathrm{Y}(\mathrm{p}, \mathrm{n}){ }^{89} \mathrm{Zr}$

The great advantage of producing ${ }^{89} \mathrm{Zr}$ from the latter two reactions is the fact that naturally occurring Yttrium is $100 \%$ composed of the ${ }^{89} \mathrm{Y}$ radionuclide (thus ${ }^{\text {nat }} \mathrm{Y}={ }^{89} \mathrm{Y}$ ). This significantly reduces the cost and availability of the target material in comparison to other radionuclides that require highly enriched materials. The first reaction ( ${ }^{\text {nat }} \mathrm{S}$ $\left.\mathrm{r}(\alpha, \mathrm{xn})^{89} \mathrm{Zr}\right)$ requires a rarely available $\alpha$-beam and is also prone to producing impurities from a differentiated strontium isotopic composition (unless enriched) so this pathway is limited to theoretical considerations.

The second reaction $\left({ }^{89} \mathrm{Y}(\mathrm{d}, 2 \mathrm{n}){ }^{89} \mathrm{Zr}\right)$, although proven to give high yields both theoretically and experimentally (Sadeghi, Enferadi, and Bakhtiari, 2012; Tang et al., 2016), requires a relatively high energy deuteron beam since its reaction threshold starts at $5.9 \mathrm{MeV}$ and peaks in the range of 13-17 MeV (Soppera, Bossant, and Cabellos, 2017b) which excludes most common small medical cyclotrons. Although the GE PETtrace 800 series is capable of producing a deuteron beam with $8.4 \mathrm{MeV}$ and the IBA Cyclone $18 / 9$ is capable of producing deuterons of $9 \mathrm{MeV}$, it is too low to yield reasonable amounts of ${ }^{89} \mathrm{Zr}$. Therefore, this pathway is reserved mostly for research centers possessing high energy, multiple beam type cyclotrons.

The third reaction $\left({ }^{89} \mathrm{Y}(\mathrm{p}, \mathrm{n})^{89} \mathrm{Zr}\right)$ is the only way for a small medical cyclotron facility to provide ${ }^{89} \mathrm{Zr}$. With radiochemical methods developed, recent worldwide research focused on target development to increase the production yields. One of the challenges is the limitation of beam energy, since above the reaction threshold of $13.08 \mathrm{MeV}$, production of long-lived ${ }^{88} \mathrm{Zr}\left(\mathrm{T}_{1 / 2}=83 \mathrm{~d}\right)$ occurs via the $(\mathrm{p}, 2 \mathrm{n})$ reaction, which is an 
impurity inseparable from the final product. Dabkowski et al. (Dabkowski et al., 2015) used a compact IBA COSTIS target, designed to produce ${ }^{89} \mathrm{Zr}$, to show that above the reaction threshold of $11.6 \mathrm{MeV}$ there is a co-production of another contaminant ${ }^{88} \mathrm{Y}$ $\left(\mathrm{T}_{1 / 2}=107 \mathrm{~d}\right)$ via ${ }^{89} \mathrm{Y}(\mathrm{p}, \mathrm{pn})^{88} \mathrm{Y}$. The yttrium atoms must be separated in the following chemistry process minimizing this amount. Below $10 \mathrm{MeV}$ proton beam energy, the authors reported a yield of insufficient quantities of ${ }^{89} \mathrm{Zr}$. This leaves a narrow beam energy window for practical use with small medical cyclotrons. For $11.6 \mathrm{MeV}$ proton beams, the yields were about $14-16 \mathrm{MBq} / \mu \mathrm{Ah}$ with maximum beam currents of $30 \mu \mathrm{A}$ in 3-3.5 h irradiation time. This gives approx. $1.4 \mathrm{GBq}$ of ${ }^{89} \mathrm{Zr}$ at EOB with a high radionuclidic purity.

In the case of custom made targets, it has been reported that one can achieve higher yields than this, while maintaining high radionuclidic purity of the final product (Sadeghi et al., 2012; Tang et al., 2016; Alfuraih et al., 2013). Custom made yttrium target developments published in recent years (Siikanen et al., 2014; Ellison et al., 2016), which encompass welding yttrium foils, modifications in yttrium foil thicknesses and water cooling, report applicable designs capable of delivering yields of up to $49 \mathrm{MBq} / \mu \mathrm{Ah}$ with maximum currents of $45 \mu \mathrm{A}$, and a $90 \%$ separation efficiency. This gives about $1.4-2.2 \mathrm{GBq}$ of radionuclidic pure ${ }^{89} \mathrm{Zr}$ in $1-2 \mathrm{~h}$ beam time, thus effectively shortening the irradiation times on the cyclotron or increasing the production capacity.

Production of ${ }^{89} \mathrm{Zr}$ using solid targets with a small medical cyclotron might be challenging because of workspace limitations. Therefore, Pandey et al. (Pandey et al., 2016) and DeGrado et al. (DeGrado et al., 2017) have studied a few cases of ${ }^{89} \mathrm{Zr}$ production via proton irradiation of liquid targets, filled with a $\mathrm{Y}\left(\mathrm{NO}_{3}\right)_{3} / \mathrm{HNO}_{3}$ solution, and corresponding chemistry. So far, their development has a much lower yield than the solid target technologies, reporting $4.4 \mathrm{MBq} / \mu \mathrm{Ah}$ with a $40 \mu \mathrm{A}$ beam current irradiated for $2 \mathrm{~h}$. This means approx. $370 \mathrm{MBq}$ of ${ }^{89} \mathrm{Zr}$ activity with $>99 \%$ radionuclidic purity which is sufficient for a very small range of applications (preclinical or a few patients on-site) and in agreement with previous work on liquid target production of ${ }^{89} \mathrm{Zr}$ (Oehlke et al., 2015).

\section{Copper-64}

Copper-64 $\left(\mathrm{T}_{1 / 2}=12.7 \mathrm{~h}, 42.5 \%\right.$ EC, $18 \% \beta_{\mathrm{av}}^{+} 278 \mathrm{keV}, 39 \% \beta_{\mathrm{av}}^{-} 190 \mathrm{keV}, 0.5 \% \gamma$ $1346 \mathrm{keV}$ ) has seen its rise starting in the late 90's and continuing in the first decade of the twenty-first century. It is one of the commonly used (mostly in the USA) nonstandard radionuclides in PET imaging thanks to several advantages (Ikotun and Lapi, 2011). Its half-life allows for shipping to distant centers, its low positron energy and little $\gamma$ emissions make the image resolution high, and high-yield and high-purity production methods are developed. Moreover, ${ }^{64} \mathrm{Cu}$ has an unexplored theranostic potential, since its positron emission is accompanied with $\beta^{-}$and abundant auger electron emission. Uses of chelated ${ }^{64} \mathrm{Cu}$ complexes are many, such as small molecules, peptides and mABs. However, the latest developments of ${ }^{89} \mathrm{Zr}$ possess the potential to take over these applications because of a longer half-life that better matches the biological half-life of the mAbs and it is cheaper to produce.

Production of ${ }^{64} \mathrm{Cu}$ is very well established. It is most commonly produced by cyclotrons utilizing a proton beam impinging on an enriched nickel-64 solid target reacting 
through a ${ }^{64} \mathrm{Ni}(\mathrm{p}, \mathrm{n})^{64} \mathrm{Cu}$ channel. The reaction threshold is $2.5 \mathrm{MeV}$ and the highest yields are achieved in the proton energy range of $10-15 \mathrm{MeV}$, well within the energy range of a small medical cyclotron. There are commercially available solid targets, based on electroplating ${ }^{64} \mathrm{Ni}$ on gold discs, which dominate the ${ }^{64} \mathrm{Cu}$ production market. In optimal situations, this method can produce up to $185 \mathrm{GBq}$ (Ikotun and Lapi, 2011) after a long beam time of up to $8 \mathrm{~h}$ and currents up to $40 \mu \mathrm{A}$ with various target thicknesses and proton energies applied, but typically lower yields are enough to supply local area customers for a few days (Avila-Rodriguez, Nye, and Nickles, 2007; Matarrese et al., 2010; Szelecsényi, Blessing, and Qaim, 1993). With radionuclide production secured, recent developments in ${ }^{64} \mathrm{Cu}$ focus on successful automation of the radiochemistry (Poniger et al., 2012; Matarrese et al., 2010; Ohya et al., 2016) and developments of reliable tracers carrying ${ }^{64} \mathrm{Cu}$ (Jalilian and Osso, 2017).

The above method, even though well-established and giving enough high purity material, is not as common as one would expect. It has a number of disadvantages (Alves et al., 2017; Jalilian and Osso, 2017):

- ${ }^{64} \mathrm{Ni}$ has a very low abundance (0.95\%), which requires significant enrichment before irradiations can be performed, making it an expensive method;

- It requires on-site electroplating equipment and recycling technology;

- Maintaining the suitable quality of electroplating (surface roughness) during long electroplating processes $(6-48 \mathrm{~h}$ ) requires careful handling (Rajec et al., 2010);

- Long irradiation times are needed occupying the accelerator;

- The operators can receive a high radiation dose unless an automated process is developed.

Thus, other methods were searched for in order to simplify the whole process. One of the options involved replacing the production pathway with ${ }^{67} \mathrm{Zn}(\mathrm{p}, \alpha){ }^{64} \mathrm{Cu}$ reaction, which was investigated by Szelecsényi et al. (Szelecsényi et al., 2014). Even though it was proven that this method is feasible for the commercial production of ${ }^{64} \mathrm{Cu}$, it offers radiochemical purity challenges and poses the same concerns regarding high enrichment of the solid target material.

The latest most interesting development, concerns producing ${ }^{64} \mathrm{Cu}$ in a liquid target as described by Alves et al. (Alves et al., 2017). Such a change would allow for a faster, safer and simplified operation with automated loading and transfer to an accompanied automated chemistry module. The group conducted a series of experiments with enriched ${ }^{64} \mathrm{Ni}$ dissolved in the novel IBA liquid target made of niobium. After an irradiation of $5 \mathrm{~h}, 4.6 \mathrm{GBq}$ of ${ }^{64} \mathrm{Cu}$ at $\mathrm{EOB}$ was produced, which translates to a yield of $0.14 \mathrm{MBq} /(\mu \mathrm{Ah} \cdot \mathrm{mg})$. The authors claim that this can easily be improved by increasing the enriched ${ }^{64} \mathrm{Ni}$ concentration and beam time to achieve up to $25 \mathrm{GBq}$ of ${ }^{64} \mathrm{Cu}$. The subsequent automated purification gave radiochemically pure ${ }^{64} \mathrm{CuCl}_{2}$ with a $77 \%$ decay corrected yield. This amount could satisfy local needs.

\section{Gallium-68 and Gallium-67}

Over the past several years, Positron Emission Tomography (PET) imaging agents labeled with gallium-68 ( $\left.{ }^{68} \mathrm{Ga}\right)$ have undergone a significant increase in clinical 
utilization. ${ }^{68} \mathrm{Ga}$ is conveniently produced from a germanium-68/gallium-68 $\left({ }^{68} \mathrm{Ge} /\right.$ ${ }^{68} \mathrm{Ga}$ ) generator. Besides gallium-68, two other gallium radionuclides are useful in nuclear medicine applications, namely ${ }^{66} \mathrm{Ga}$ and ${ }^{67} \mathrm{Ga}$. Only ${ }^{67} \mathrm{Ga}$, besides ${ }^{68} \mathrm{Ga}$, is used routinely in clinical applications. ${ }^{66} \mathrm{Ga}\left(\mathrm{T}_{1 / 2}=9.5 \mathrm{~h}, 44 \% \mathrm{EC}^{+} \beta^{+}, 51 \% \beta_{\mathrm{av}}^{+} 1904 \mathrm{keV}, 37 \%\right.$

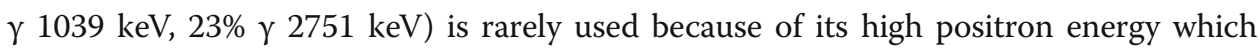
lowers the resolution of images combined with a high patient dose as it emits multiple $\gamma$ rays of energies above $1 \mathrm{MeV}$. Currently, sufficient base of evaluated nuclear data exists for the production of these radionuclides (Aslam, Amjed, and Qaim, 2015).

${ }^{68} \mathrm{Ga}\left(\mathrm{T}_{1 / 2}=67.7 \mathrm{~min}, 100 \% \mathrm{EC}^{+} \beta^{+}, 88 \% \beta_{\mathrm{av}}^{+} 836 \mathrm{keV}, 3 \% \gamma 1077 \mathrm{keV}\right)$ became the radionuclide of particular interest. Its half-life is relatively short, but it is often irrelevant since the majority of ${ }^{68} \mathrm{Ga}$ is available at nuclear medicine departments from ${ }^{68} \mathrm{Ge} /$ ${ }^{68} \mathrm{Ga}$ generators (Germanium has a half-life of 271 days) and the short half-life lowers the patient dose. Together with well-known radiochemistry and kit-based preparation methods, ${ }^{68} \mathrm{Ga}$ development accelerated, finding application mostly in peptide-based tracers, antibodies and small research molecules (Jalilian, 2016). It is also a possible candidate for further theranostic use. Many ${ }^{68} \mathrm{Ga}$-labelled tracers are used in clinical trials and some are already approved by local authorities: ${ }^{68} \mathrm{Ga}$-DOTATATE (approved by the US Food and Drug Agency in the USA) and SomaKit TOC ${ }^{\mathrm{mm}}$ (approved by the European Medicines Agency) (Brief, 2016; Applications, 2016). For neuroendocrine tumor imaging in the UK, Gallium-68 based PET scans were recently advised as a replacement for ${ }^{111}$ In based SPECT scans (Kalsy and Vinjamuri, 2016).

Radiochemically pure Germanium-68 is produced via several alternative routes, mostly using a nat,69 $\mathrm{Ga}(\mathrm{p}, \mathrm{xn}){ }^{68} \mathrm{Ge}$ nuclear reaction on higher proton energy cyclotrons of $>20 \mathrm{MeV}$, capable of delivering beam intensities of up to a few hundred microamperes for up to a few weeks of irradiation time (IAEA, 2010). This requires a robust and complex solid target design that can handle a high heat transfer for prolonged periods, as well as reliable purification of the material once the irradiation is complete. The rising need for ${ }^{68} \mathrm{Ga}$ radionuclide fuels developments in this area (Fitzsimmons and Mausner, 2015a; Fitzsimmons and Mausner, 2015b; Sounalet et al., 2014; Bach et al., 2013).

${ }^{68} \mathrm{Ge} /{ }^{68} \mathrm{Ga}$ generators have worldwide coverage. Still, small cyclotron production of ${ }^{68} \mathrm{Ga}$ is possible by bombardment by protons on an enriched ${ }^{68} \mathrm{Zn}$ or ${ }^{\text {nat }} \mathrm{Zn}$ target (Engle et al., 2012) since the nuclear reaction of ${ }^{68} \mathrm{Zn}(\mathrm{p}, \mathrm{n})^{68} \mathrm{Ga}$ has a high cross section of up to $1 \mathrm{~b}$ in the energy range of $11-14 \mathrm{MeV}$. However, this method cannot compete with the ${ }^{68} \mathrm{Ge} /{ }^{68} \mathrm{Ga}$ generators when it comes to issues such as:

- complex solid target handling and development;

- the need for enriched material;

- acceptance of inseparable impurities of ${ }^{66} \mathrm{Ga}$ and ${ }^{67} \mathrm{Ga}$.

The comparison looks different when it comes to direct medical cyclotron productions using liquid targets, allowing for fast, small scale on-site productions of radiochemically pure ${ }^{68} \mathrm{Ga}$. Such a method, based on a ${ }^{68} \mathrm{Zn}(\mathrm{p}, \mathrm{n}){ }^{68} \mathrm{Ga}$ reaction, would be of particular benefit for hospital cyclotron facilities with spare capacity to add a ${ }^{68} \mathrm{Ga}$ tracer to their routine operations. To achieve a high purity of ${ }^{68} \mathrm{Ga}$ from direct irradiation of enriched ${ }^{68} \mathrm{Zn}$, the proton beam energy must be optimized since the threshold 
for producing the ${ }^{67} \mathrm{Ga}$ contaminant from competing ${ }^{68} \mathrm{Zn}(\mathrm{p}, 2 \mathrm{n}){ }^{67} \mathrm{Ga}$ is $12 \mathrm{MeV}$, so in the peak area of the ${ }^{68} \mathrm{Ga}$ production cross-section. Works toward achieving liquid target technology were initiated by Pandey et al., the same group that was mentioned before for the development of Zr-89 liquid target (Pandey et al., 2014b). They proposed a dissolution of enriched $\mathrm{Zn}^{68}$ target material in nitric acid. The authors claim that they achieved a cheap method for producing small quantities of radiochemically pure ${ }^{68} \mathrm{Ga}$ for 2-4 patients in a beam time of approx. $1 \mathrm{~h}$. Furthermore, a recent study using a novel IBA target was carried out by Alves et al. (Alves et al., 2017), the same research publication that described the possibilities of liquid target ${ }^{64} \mathrm{Cu}$ production. The results look very promising. A $45 \mathrm{~min}$ irradiation of $30 \mathrm{mg} / \mathrm{ml}$ of ${ }^{68} \mathrm{Zn}$ with a $45 \mu \mathrm{A}$ proton beam yielded $6 \mathrm{GBq}$ of ${ }^{68} \mathrm{Ga}$, which can be translated to achieving batches of $40 \mathrm{GBq}$ of ${ }^{68} \mathrm{Ga}$ (pre-purification) by optimization of concentration and beam parameters. This can create a viable alternative for solid target and generator produced ${ }^{68} \mathrm{Ga}$. Besides general advantages of using a solution target instead of solid target, no long lived ${ }^{68} \mathrm{Ge}$ impurities were found in the final product. Authors of both above mentioned works also motivate their studies with the need to prevent ${ }^{68} \mathrm{Ge}$ breakthrough that occurs in generators, but this argument seems less relevant since today's modern generators have included mechanisms that nullify that effect (Roesch, 2012a).

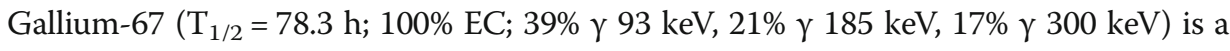
less widely used SPECT imaging agent, but has a potential for broader usage. Its most notably used tracer worldwide is ${ }^{67} \mathrm{Ga}$ citrate in various inflammatory studies leading to the detection of tumors and infections (Cwikla et al., 1999; Jalilian et al., 2009). ${ }^{67}$ Ga could also become a therapeutic agent in the future due to the emission of Auger electrons.

Several possible pathways for the production of ${ }^{67} \mathrm{Ga}$ exist from proton to deuteron (Tárkányi et al., 2004) and alpha beams. The most commonly used method is proton irradiation of solid targets of either enriched or natural zinc, inducing a ${ }^{68} \mathrm{Zn}$ $(\mathrm{p}, 2 \mathrm{n}){ }^{67} \mathrm{Ga}$ reaction (reaction threshold $10.3 \mathrm{MeV}$ ) and a ${ }^{67} \mathrm{Zn}(\mathrm{p}, \mathrm{n}){ }^{67} \mathrm{Ga}$ reaction (reaction threshold $1.8 \mathrm{MeV}$ ) (Aslam et al., 2015; Asad et al., 2014). ${ }^{68} \mathrm{Zn}(\mathrm{p}, 2 \mathrm{n}){ }^{67} \mathrm{Ga}$ requires a higher energy cyclotron as the reaction cross-section peaks around $21 \mathrm{MeV}$. It will inevitably lead to the co-production of large amounts of ${ }^{68} \mathrm{Ga}$, creating the need to wait until this impurity level is reduced to acceptable limits. $50 \mathrm{GBq}$ was reportedly produced in one batch with this method (Qaim, 2012). Since ${ }^{67} \mathrm{Ga}$ is the longest lived of gallium radionuclides and waiting time for removal of impurities is applied, this method can also use natural zinc targets, considerably reducing costs and employing both reaction pathways. Such a method was presented by Martins et al. (Martins and Osso, 2013) where the authors investigated a new ${ }^{67} \mathrm{Ga}$ purification technique, resulting in radionuclidic pure $(99.9 \%){ }^{67} \mathrm{Ga}$ production yields of $40 \mathrm{MBq} / \mu \mathrm{Ah}$ with a $26 \mathrm{MeV}$ proton beam on a natural zinc solid target. One must also consider unavoidable losses connected to the extraction efficiency (72\%) and decay period of 3 days.

Channel ${ }^{67} \mathrm{Zn}(\mathrm{p}, \mathrm{n})^{67} \mathrm{Ga}$ offers an alternative for use in small medical cyclotrons that do have enough proton beam energy. To make it efficient, one must consider expensive enrichment since the natural abundance of ${ }^{67} \mathrm{Zn}$ is very low (4\%). Staying below the $13 \mathrm{MeV}$ production threshold for ${ }^{66} \mathrm{Ga}$ will not require unnecessary decay-out time for the byproducts. Even though this method is theoretically feasible, it is not commercially implemented. To our opinion, this is due to the fact that the long half-life of 3.3 days allows for an easy distribution of this nuclide. A single intermediate energy cyclotron may easily cover 
regional needs, so implementing a time-consuming, solid, enriched target ${ }^{67} \mathrm{Ga}$ production process on a small medical cyclotron has little economical justification. Perhaps with further increasing demand for this nuclide, small scale production sites will be needed.

\section{Indium-111}

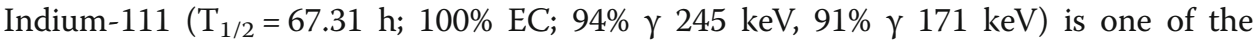
classical radionuclides used in SPECT studies, thanks to its favorable low-energy and high-intensity emissions, and half-life suitable for in vivo studies. Possible medical uses are enormous (Lahiri, Maiti, and Ghosh, 2013), with monoclonal antibodies labeling, blood cell labeling for migration studies, tumor imaging, diabetes studies and more. ${ }^{111}$ In can also be considered an Auger electron therapy agent (Qaim, 2012). ${ }^{111}$ I is not only used in nuclear medicine, but also in material science(Lahiri et al., 2013).

Currently, the most common production route for ${ }^{111} \mathrm{In}$ is via proton irradiation of highly enriched Cadmium-112 solid targets, through reaction pathway ${ }^{112} \mathrm{Cd}(\mathrm{p}, 2 \mathrm{n})^{111} \mathrm{In}$. It is carried out by intermediate energy cyclotrons with protons of an energy range of $25 \mathrm{MeV}$, with the peak reaction rate around 20-22 MeV (cross section approx. 1000 $\mathrm{mb})$. This method offers high yields $(248 \mathrm{MBq} / \mu \mathrm{Ah})$ with co-produced impurities of ${ }^{112} \mathrm{Cd}$ and ${ }^{112} \mathrm{Sn}$, which are later separated. Batches of $50 \mathrm{GBq}$ are reportedly produced on a regular basis (Qaim, 2017).

Despite being a well-established classical cyclotron produced radionuclide, it can be produced using novel methods employing SMC. From this point of view, only nuclear reaction ${ }^{111} \mathrm{Cd}(\mathrm{p}, \mathrm{n}){ }^{111} \mathrm{In}$ is feasible (Alipoor, Gholamzadeh, and Sadeghi, 2011). It peaks at $15 \mathrm{MeV}$ with approximately $800 \mathrm{mb}$ reaction cross section. A theoretical yield of $67.5 \mathrm{MBq} / \mu \mathrm{Ah}$ is expected, which is 4 times less than the one used in the intermediate energy range cyclotrons. An advantage is that up to $20 \mathrm{MeV}$ no considerable co-production of isotopic impurities is expected. However, no literature on such experimental production attempts were found. It is doubtful that this method would find enough interest among small medical cyclotron users, as the radionuclide is readily available in sufficient amounts.

\section{Yttrium-86}

Yttrium-86 $\left(\mathrm{T}_{1 / 2}=14.7 \mathrm{~h}, 100 \% \mathrm{EC}^{+} \beta^{+} ; 12 \% \beta_{\mathrm{av}}^{+} 535 \mathrm{keV}, 6 \% \beta_{\mathrm{av}}^{+} 681 \mathrm{keV}, 83 \% \gamma\right.$ $1077 \mathrm{keV}$ ) can be considered a very special PET radionuclide. If it was not for the widely used therapeutic agent ${ }^{90} \mathrm{Y}\left(\mathrm{T}_{1 / 2}=2.67 \mathrm{~d}, 100 \% \beta_{\mathrm{av}}^{-} 934 \mathrm{keV}\right),{ }^{86} \mathrm{Y}$ would probably not receive any special attention. Its positrons have relatively low intensity and high energy for imaging in proper resolution. However, there is a big advantage of being the surrogate of the therapeutic nuclide - it can be used as a biodistribution imaging agent with the use of the same tracers, with already implemented labeling methods. This is especially important as ${ }^{90} \mathrm{Y}$ is a pure $\beta^{-}$emitter, offering only very limited SPECT imaging due to brehmsstrahlung effect. $\mathrm{A}^{86} \mathrm{Y} /{ }^{90} \mathrm{Y}$ labeled mixture administered to the patient is a good example of a theranostic application, allowing simultaneous therapy with PET imaging (Rösch, Herzog, and Qaim, 2017).

Zaneb et al. (Zaneb et al., 2015) has theoretically proven that ${ }^{86} \mathrm{Y}$ is best produced on small medical cyclotrons using a ${ }^{86} \mathrm{Sr}(\mathrm{p}, \mathrm{n}){ }^{86} \mathrm{Y}$ nuclear reaction. It is predicted that the yield for this reaction is for $371 \mathrm{MBq} / \mu \mathrm{Ah}$ assuming $100 \%$ enrichment of the solid target and irradiation by $14 \mathrm{MeV}$ protons. The main competitive method against it is 
${ }^{88} \mathrm{Sr}(\mathrm{p}, 3 \mathrm{n}){ }^{86} \mathrm{Y}$, which offers an almost 3-fold higher integral yield (1005 MBq/ $\left.\mu \mathrm{Ah}\right)$, but requires an energy range of $43-33 \mathrm{MeV}$. The advantage of the latter process is that ${ }^{88} \mathrm{Sr}$ is a much more abundant stable isotope of strontium (82.5\% compared to $9.7 \%$ for ${ }^{86} \mathrm{Sr}$ ), which can translate into a lower cost of enriched materials. However, the high energy range still requires a rare high energy cyclotron, and there are serious considerations with impurity levels of ${ }^{87 \mathrm{~m}} \mathrm{Y},{ }^{87 \mathrm{~m}} \mathrm{Y}$, and ${ }^{85} \mathrm{Y}$. The two factors combined render the second method uninteresting.

Production via the ${ }^{86} \mathrm{Sr}(\mathrm{p}, \mathrm{n})^{86} \mathrm{Y}$ reaction can give a product of high radionuclidic purity. A highly present by-product is ${ }^{86 \mathrm{~m}} \mathrm{Y}\left(\mathrm{T}_{1 / 2}=48 \mathrm{~min}\right)$, but it decays to ${ }^{86} \mathrm{Y}$ which turns out to simply increase nuclide production after EOB and should not be considered an impurity. Target post irradiation cooling and post processing of the nuclide considerably lower the amount of ${ }^{86 \mathrm{~m}} \mathrm{Y}$ at the End of Synthesis (EOS). Reischl et al. (Reischl, Roesch, and Machulla, 2002) irradiated a 95.6\% enriched solid ${ }^{86} \mathrm{SrCO}_{3}$ target with $15.1 \mathrm{MeV}$ protons which resulted in average production yields of $48 \mathrm{MBq} / \mu \mathrm{Ah}$ with a radionuclidic purity of $>99 \%$ at EOB. The later separation by electrolysis $(1 \mathrm{~h})$ gives separation yields of $97 \%$, no carrier-added. Using a $10 \mu \mathrm{A}$ beam over $2.5 \mathrm{~h}$, this results in $1 \mathrm{GBq}$ of purified ${ }^{86} \mathrm{Y}$. Yoo et al. (Yoo et al., 2005) achieved the same separation yield and radionuclidic purity using a very similar setup. They had the same enrichment of ${ }^{86} \mathrm{Sr}$ and used electrolysis for separation (with different parameters taking up to $3 \mathrm{~h}$ ). A different target was used, namely $\mathrm{SrO}$, and $2 \mu \mathrm{A}, 14.5 \mathrm{MeV}$ proton beams for $2 \mathrm{~h}$ resulted in much higher yields of $166 \mathrm{MBq} / \mu \mathrm{Ah}$. A few years later, a study by Avila-Rodriguez et al. (Avila-Rodriguez, Nye, and Nickles, 2008) revealed a faster separation method using filtration that takes only $20 \mathrm{~min}$. They used several $11 \mathrm{MeV}$ proton beams of $10 \mu \mathrm{A}$ for $2 \mathrm{~h}$ using a $97 \%$ enriched strontium ${ }^{86} \mathrm{SrCO}_{3}$ target. Even though this method is faster, it has a lower separation efficiency of $88 \%$, results in carrier presence in the order of tens of ppm's and has a lower radionuclidic purity of $97 \%$ at $\mathrm{EOB}$ (excluding ${ }^{86 \mathrm{~m}} \mathrm{Y}$ ) with $2.5 \%{ }^{87 \mathrm{~m}} \mathrm{Y}$. The yield was $44 \mathrm{MBq} / \mathrm{h}$ - so in the same range as Reischl et al. (Reischl et al., 2002) - which confirms the superiority of SrO targets used by Yoo et al. (Yoo et al., 2005). ${ }^{86} \mathrm{Sr}$ was fully recyclable in all cases.

The above mentioned works result in delivering an approximate amount of $1 \mathrm{GBq}$ of ${ }^{86} \mathrm{Y}$ labeled tracer which, in conjunction with ${ }^{90} \mathrm{Y}$ therapy agents, could satisfy the need for a few patients.

An experiment is reported on ${ }^{86} \mathrm{Y}$ production using liquid targets. Oehlke et al. (Oehlke et al., 2015) irradiated a $0.9 \mathrm{ml}$ Niobium-body Havar-window liquid target with a $13 \mathrm{MeV}$ proton beam from a small medical cyclotron. The solution contained ${ }^{\text {nat }} \mathrm{Sr}$ $\left(\mathrm{NO}_{3}\right)_{2}$ salt dissolved in ultrapure water. Beam conditions were $4.6 \mu \mathrm{A}$ in average, running for $1 \mathrm{~h}$. The separation using DGA resin was 99\% efficient. The resulting yield was $1.44 \mathrm{MBq} / \mu \mathrm{Ah}$, considerably lower than the above mentioned solid target results, but it is worth mentioning that natural strontium was used with a 10 times lower content of ${ }^{86} \mathrm{Sr}$ than enriched material. By doing a simplified estimation, using an enriched material could give us an increase in yield of 10 times to $14 \mathrm{MBq} / \mu \mathrm{Ah}$. Small medical cyclotrons can have 2-3 higher target volumes than reported here - a further increase of the target volume could provide another yield increase. There is also room left to adjust the concentration of the salt. In conclusion, a liquid target method is a possible alternative for easier production of Yttrium-86 on a small scale. 


\section{Scandium-44}

One of the very recent radionuclides of interest for PET imaging is ${ }^{44} \mathrm{Sc}\left(\mathrm{T}_{1 / 2}=3.97 \mathrm{~h}\right.$, $\left.100 \% \mathrm{EC}^{+} \beta^{+}, 94 \% \beta_{\mathrm{av}}^{+} 632 \mathrm{keV}, 100 \% \gamma 1157 \mathrm{keV}\right)$. Due to the chemical similarity of $\mathrm{Sc}^{3+}$ cation to $\mathrm{Lu}^{3+}$ and $\mathrm{Y}^{3+}$, DOTA complexes labeled with those radionuclides show very similar properties in vivo. This makes it a possible diagnostic surrogate for therapeutic tracers containing ${ }^{177} \mathrm{Lu}$ or ${ }^{90} \mathrm{Y}$. Currently, $\left[{ }^{68} \mathrm{Ga}\right] \mathrm{Ga}$-DOTA-complexes are used for this purpose (Krajewski et al., 2013). ${ }^{44} \mathrm{Sc}$ shows superiority over Gallium-68, given that the routine production method is well established. It does not require an expensive ${ }^{68} \mathrm{Ge} /$ ${ }^{68} \mathrm{Ge}$ generator, it has a half-life suitable for logistics, a lower positron energy and slightly higher $\beta^{+}$branching ratio. Moreover, ${ }^{47} \mathrm{Sc}\left(\mathrm{T}_{1 / 2}=3.35 \mathrm{~d}, 100 \% \beta^{-}, 69 \% \beta_{\mathrm{av}}^{-}\right.$

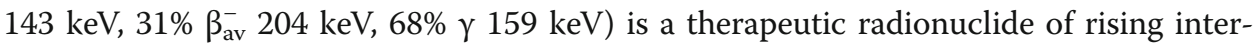
est, which creates possibilities for a theranostic agent by applying a matched pair of ${ }^{44} \mathrm{Sc} /{ }^{47} \mathrm{Sc} .{ }^{44} \mathrm{Sc}$ can also be used independently in peptide based imaging, as well as antibody labeling and small protein labeling (Hernandez et al., 2014).

Multiple methods for the production of ${ }^{44} \mathrm{Sc}$ have been investigated. Experiments were done with an $\alpha$ - beam at $29 \mathrm{MeV}$ (Szkliniarz et al., 2016), a deuteron beam at $16 \mathrm{MeV}$ (Alliot et al., 2015) and an innovative method employing a ${ }^{44 \mathrm{~m}} \mathrm{Sc} /{ }^{44} \mathrm{Sc}$ in vivo generator (Huclier-Markai et al., 2014). In the latter case, the in vivo generator utilizes the existence of the metastable state of ${ }^{44 \mathrm{~m}} \mathrm{Sc}$ (otherwise treated as impurity) that decays by internal transition $(98.8 \%)$ to ${ }^{44} \mathrm{Sc}$, which later emits positrons used for imaging. This way, the long half-life of ${ }^{44 \mathrm{~m}} \mathrm{Sc}\left(\mathrm{T}_{1 / 2}=58.6 \mathrm{~h}\right)$ allows for longer pharmacokinetic studies, which is especially important when dealing with $\mathrm{mABs}$. Additionally, ${ }^{44 \mathrm{~m}} \mathrm{Sc}$ is closer with its half-life to the therapeutic isotope ${ }^{44} \mathrm{Sc}$ ( 2.44 vs $3.35 \mathrm{~d}$ ), making it possible to monitor drug metabolism over a longer period of time. Huclier-Markai et al. (Huclier-Markai et al., 2014) prove that the recoil energy of the decay of the metastable state, which is only $271 \mathrm{keV}$ above its daughter state of ${ }^{44} \mathrm{Sc}$, is too low $(0.89 \mathrm{eV})$ for the isotope to leave the chelator molecule, thus assuring stability of the complexes used.

Another method to acquire ${ }^{44} \mathrm{Sc}$ is the ${ }^{44} \mathrm{Ti} /{ }^{44} \mathrm{Sc}$ generator (Roesch, 2012b; Filosofov, Loktionova, and Rösch, 2010). There, the parent nuclide of ${ }^{44} \mathrm{Ti}(60.6 \mathrm{y}, 100 \% \mathrm{EC}, 93 \%$

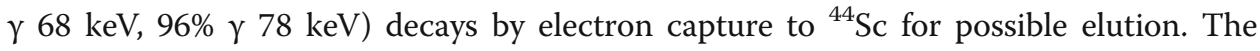
concept is based indirectly on the usage of cyclotrons, as the ${ }^{44} \mathrm{Ti}$ is produced by a ${ }^{45} \mathrm{Sc}(\mathrm{p}, 2 \mathrm{n}){ }^{44} \mathrm{Ti}$ reaction. An especially advantageous factor of this method is that ${ }^{45} \mathrm{Sc}$ is the only naturally occurring stable isotope of scandium; therefore, there is no need to acquire expensive enriched material for irradiations. The peak cross section for this reaction is around $20 \mathrm{MeV}$ proton energy (Soppera et al., 2017a), but the ${ }^{44} \mathrm{Ti}$ production method is inappropriate for utilization by SMCs as production of very long-lived ${ }^{44} \mathrm{Ti}$ would require a relatively high proton beam current, which is typically not possible with SMCs. For this reason, Filosofov et al. [104]produced $185 \mathrm{MBq}$ of ${ }^{44} \mathrm{Ti}$ on an intermediate energy cyclotron with proton energies of $25 \mathrm{MeV}$ and a beam current of $200 \mu \mathrm{A}$. The final proposed generator allowed them to elute $180 \mathrm{MBq}$ of Scandium on a weekly basis, which was continued for a year. The authors report a negligible amount of ${ }^{44} \mathrm{Ti}$ breakthrough in the order of $10^{-5} \mathrm{~Bq}$. However, additional post processing steps are required to obtain a ${ }^{44} \mathrm{Sc}$ solution. Additionally, long elution intervals and little amounts of final product are a certain limitation of the method, which can be countered only by intensive irradiations that could increase the amount of ${ }^{44} \mathrm{Ti}$. 
In the case of small medical cyclotrons the common production route is via the ${ }^{44} \mathrm{Ca}(\mathrm{p}, \mathrm{n}){ }^{44} \mathrm{Sc}$ nuclear reaction by using a solid target irradiation of highly enriched ${ }^{44} \mathrm{CaCO}_{3}$ powder. The reaction cross section maximum reaches approx. Eight hundred mb for $11 \mathrm{MeV}$ protons. ${ }^{44 \mathrm{~m}} \mathrm{Sc}\left(\mathrm{T}_{1 / 2}=58.6 \mathrm{~h}, 99 \% \mathrm{IT}, 87 \% \gamma 271 \mathrm{keV}\right)$ is an impurity of concern, although the energy of the $\gamma$ does not carry a risk to patients or the PET image resolution. Its long half-life creates the effect of the in-vivo generator mentioned before. The reaction ${ }^{44} \mathrm{Ca}(\mathrm{p}, \mathrm{n}){ }^{44 \mathrm{~m}} \mathrm{Sc}$ cross-section reaches almost $100 \mathrm{mb}$ and peaks at $13 \mathrm{MeV}$.

Krajewski et al. (Krajewski et al., 2013) presented an optimization study on the ${ }^{44} \mathrm{Ca}(\mathrm{p}, \mathrm{n}){ }^{44} \mathrm{Sc}$ reaction pathway which reports $9 \mathrm{MeV}$ to be the best optimized proton energy, giving $>99 \%$ radionuclidic purity with only $0.09 \%{ }^{44 \mathrm{~m}} \mathrm{Sc}$ content in the finished product. Other impurities of ${ }^{43} \mathrm{Sc},{ }^{46} \mathrm{Sc},{ }^{47} \mathrm{Sc}$ and ${ }^{48} \mathrm{Sc}$ were negligible or not detectable at all. $4 \mathrm{~h}$ irradiation of $20 \mathrm{mg}$ of enriched $\left[{ }^{44} \mathrm{Ca}\right] \mathrm{CaCO}_{3}$ with $12,4 \mu \mathrm{A}$ beam resulted in $2.5 \mathrm{GBq}$ of ${ }^{44} \mathrm{Sc}$. The further separation yield was $70 \%$, calcium content measured by ICP-MS analysis was below $1 \mathrm{ppm}$. Further labeling yield with DOTA-TATE was > $98 \%$, and the target recycling efficiency was only $60 \%$. Other research groups have reached higher separation efficiencies of $80 \%$ (Valdovinos et al., 2015), and high radiochemical yields with different tracers above $90 \%$ (Hernandez et al., 2014), but their use of natural calcium as a target limits the production yield and radionuclidic purity, which in turn is not of use in clinical applications.

Recently published work by Meulen et al. (Meulen et al., 2015) presented a more efficient process and confirmed that the low energy range gave the best results, with an $11 \mathrm{MeV}$ proton beam on $10 \mathrm{mg}$ of $97 \%$ enriched ${ }^{44} \mathrm{CaCO}_{3}$ target. With an improved target design, they were able to irradiate with $50 \mu \mathrm{A}$, hence using a shorter time of $90 \mathrm{~min}$, reaching $1.9 \mathrm{GBq}$ of ${ }^{44} \mathrm{Sc}$ at $\mathrm{EOB}$ (note the amount of irradiated material is halved in comparison to the above study (Krajewski et al., 2013)). Moreover, the group reports a faster and very efficient separation method with $98 \%$ efficiency with $<1$ ppm metallic contaminant levels. Radionuclidic purity was $99 \%$ and further radiolabelling efficiencies with DOTANOC were $>98 \%$. The study also showed great improvement in the recycling of enriched calcium reaching $98 \%$ of initial enriched material recovery, significantly reducing the operational costs in comparison to work of Krajewski et al. (Krajewski et al., 2013). The required proton energy is low enough for almost all small medical cyclotrons, provided that the use of the solid target is accepted. The disadvantage of the method is certainly the cost of ${ }^{44} \mathrm{Ca}$. Its natural abundance is only $2.1 \%$, therefore $97 \%$ enriched ${ }^{44} \mathrm{CaCO}_{3}$ costs about $\$ 15 / \mathrm{mg}$ (Meulen et al., 2015). Fortunately, the material is highly recyclable.

${ }^{44} \mathrm{Sc}$ was also investigated by Oehlke et al. for the production in a liquid target (Hoehr et al., 2014). Thirteen $\mathrm{MeV}$ proton beam irradiated natural calcium nitrate $\mathrm{Ca}\left(\mathrm{NO}_{3}\right)_{2}$ in dissolved in ultrapure water, in a relatively small volume target of $0.9 \mathrm{ml}$. The authors report a maximum of $28 \mathrm{MBq}$ at EOB with a $20 \mu \mathrm{A}$ beam current for $1 \mathrm{~h}$, which may seem disappointing from a clinical perspective. However, a number of alterations could prove the method to be viable such as: increasing the beam time, target volume and concentration, and most importantly, a high enrichment of ${ }^{44} \mathrm{Ca}$ could elevate the produced activity to GBq level.

\section{Less common radionuclides in small medical cyclotron energy range}

There are many other non-standard radionuclides that can be produced using small medical cyclotrons, but currently the usage of them is limited, either because 
of a lack of developed applications, scarce nuclear data, or significant investment needs. In a recent, impressive work by Qaim (Qaim, 2017), a list of such nuclides is presented. Less common diagnostic purpose radionuclides of increasing interest are especially: ${ }^{51} \mathrm{Cr},{ }^{45} \mathrm{Ti},{ }^{76} \mathrm{Br},{ }^{90} \mathrm{Nb}$ or ${ }^{94 \mathrm{~m}} \mathrm{Tc}$.

Therapeutic radionuclides are mostly produced in nuclear reactors and, due to their nature, are most often $\beta^{-}$emitters. These are, in general, neutron rich elements. However, there are also pathways possible for the production of therapeutic radionuclides using small medical cyclotrons such as ${ }^{67} \mathrm{Cu},{ }^{186} \mathrm{Re},{ }^{103} \mathrm{Pd}$ and ${ }^{225}$ Ac (Qaim, 2017), but those nuclides are reported to be very expensive (Zimmermann, 2013).

Table 4 Comparison of the properties of presented radionuclides

\begin{tabular}{|c|c|c|c|c|c|c|c|}
\hline $\begin{array}{l}\text { Radionuclide } \\
\text { (in order of } \\
\text { appearance) }\end{array}$ & $\begin{array}{l}\text { Imaging } \\
\text { procedure }\end{array}$ & $T_{1 / 2}$ & I & $\begin{array}{l}E_{\gamma} \text { or } \\
E_{\text {av. } \beta} \\
(k e V)\end{array}$ & $\begin{array}{l}\text { Feasible SMC } \\
\text { (<20 MeV) } \\
\text { nuclear reaction }\end{array}$ & $\begin{array}{l}\text { Target } \\
\text { type }\end{array}$ & Yield \\
\hline${ }^{99 \mathrm{~m}} \mathrm{Tc}$ & SPECT & $6.43 \mathrm{~h}$ & ү 99\% & 140.5 & ${ }^{100} \mathrm{Mo}(\mathrm{p}, 2 \mathrm{2})^{99 \mathrm{~m}} \mathrm{Tc}$ & Solid & $\begin{array}{l}513 \mathrm{MBq} / \mu \mathrm{Ah} \\
\text { (Benard et al., } \\
\text { 2014) }\end{array}$ \\
\hline 123 & SPECT & $13.2 \mathrm{~h}$ & ү $83 \%$ & 158 & ${ }^{123} \mathrm{Te}(\mathrm{p}, \mathrm{n})^{123}$ & Solid & No data \\
\hline $124 \mid$ & PET & $4.18 d$ & $\begin{array}{l}\beta^{+} 12 \% \\
\beta^{+} 11 \% \\
\gamma 63 \%\end{array}$ & $\begin{array}{l}687 \\
975 \\
603\end{array}$ & ${ }^{124} \mathrm{Te}(\mathrm{p}, \mathrm{n}){ }^{124}$ & Solid & $\begin{array}{l}21 \mathrm{MBq} / \mu \mathrm{Ah} \\
\text { (Braghirolli } \\
\text { et al., 2014) }\end{array}$ \\
\hline${ }^{89} \mathrm{Zr}$ & PET & $78.4 \mathrm{~h}$ & $\begin{array}{l}\beta^{+} 23 \% \\
\text { y } 99 \%\end{array}$ & $\begin{array}{l}396 \\
909\end{array}$ & ${ }^{89} \mathrm{Y}(\mathrm{p}, \mathrm{n}){ }^{89} \mathrm{Zr}$ & $\begin{array}{l}\text { Solid } \\
\text { Liquid }\end{array}$ & $\begin{array}{l}49 \mathrm{MBq} / \mu \mathrm{Ah} \\
\text { (Siikanen et al., } \\
\text { 2014) } \\
4.4 \mathrm{MBq} / \mu \mathrm{Ah} \\
\text { (Pandey et al., } \\
\text { 2016) }\end{array}$ \\
\hline${ }^{64} \mathrm{Cu}$ & PET & $12.7 \mathrm{~h}$ & $\begin{array}{l}\beta^{+} 18 \% \\
\beta^{-} 39 \% \\
\gamma 0.5 \%\end{array}$ & $\begin{array}{l}278 \\
190 \\
134\end{array}$ & ${ }^{64} \mathrm{Ni}(\mathrm{p}, \mathrm{n}){ }^{64} \mathrm{Cu}$ & $\begin{array}{l}\text { Solid } \\
\text { Liquid }\end{array}$ & $\begin{array}{l}304 \mathrm{MBq} / \mu \mathrm{Ah} \\
\text { (Qaim, 2017) } \\
0.14 \mathrm{MBq} / \\
\text { ( } \mu \text { Ah.mg) } \\
\text { (Alves et al., } \\
\text { 2017) }\end{array}$ \\
\hline${ }^{68} \mathrm{Ga}$ & PET & $67.7 \mathrm{~min}$ & $\begin{array}{l}\beta^{+} 88 \% \\
\text { ү } 3 \%\end{array}$ & $\begin{array}{l}836 \\
1077\end{array}$ & ${ }^{68} \mathrm{Zn}(\mathrm{p}, \mathrm{n}){ }^{68} \mathrm{Ga}$ & $\begin{array}{l}\text { Solid } \\
\text { Liquid }\end{array}$ & $\begin{array}{l}\text { No data } \\
1.5 \mathrm{MBq} / \\
(\mu \mathrm{Ah} \cdot \mathrm{mg}) \\
\text { (Alves et al., } \\
2017)\end{array}$ \\
\hline${ }^{67} \mathrm{Ga}$ & SPECT & $78.3 \mathrm{~h}$ & $\begin{array}{l}\text { y } 39 \% \\
\text { y } 21 \% \\
\text { y } 17 \%\end{array}$ & $\begin{array}{l}93 \\
185 \\
300\end{array}$ & $\begin{array}{l}{ }^{68} \mathrm{Zn}(\mathrm{p}, 2 \mathrm{n}){ }^{67} \mathrm{Ga} \\
{ }^{67} \mathrm{Zn}(\mathrm{p}, \mathrm{n})^{67} \mathrm{Ga}\end{array}$ & Solid & No data \\
\hline${ }^{111} \ln$ & SPECT & $67.3 \mathrm{~h}$ & $\begin{array}{l}\text { ү } 94 \% \\
\text { ү } 91 \%\end{array}$ & $\begin{array}{l}245 \\
171\end{array}$ & ${ }^{111} \mathrm{Cd}(\mathrm{p}, \mathrm{n})^{111} \ln$ & Solid & $\begin{array}{l}67.5 \mathrm{MBq} / \\
\text { Ah (Alipoor } \\
\text { et al., 2011) }\end{array}$ \\
\hline${ }^{86} Y$ & PET & $14.7 \mathrm{~h}$ & $\begin{array}{l}\beta^{+} 12 \% \\
\beta^{+} 6 \% \\
\gamma 83 \%\end{array}$ & $\begin{array}{l}535 \\
681 \\
1077\end{array}$ & ${ }^{86} \operatorname{Sr}(p, n)^{86} Y$ & $\begin{array}{l}\text { Solid } \\
\text { Liquid }\end{array}$ & $\begin{array}{l}166 \mathrm{MBq} / \mu \mathrm{Ah} \\
\text { (Yoo et al., } \\
2005) \\
1.44 \mathrm{MBq} / \mu \mathrm{Ah} \\
\text { (Oehlke et al., } \\
\text { 2015) }\end{array}$ \\
\hline${ }^{44} \mathrm{SC}$ & PET & $3.97 \mathrm{~h}$ & $\begin{array}{l}\beta^{+} 94 \% \\
\text { y } 100 \%\end{array}$ & $\begin{array}{l}632 \\
1157\end{array}$ & ${ }^{44} \mathrm{Ca}(\mathrm{p}, \mathrm{n})^{44} \mathrm{SC}$ & $\begin{array}{l}\text { Solid } \\
\text { Liquid }\end{array}$ & $\begin{array}{l}25 \mathrm{MBq} / \mu \mathrm{Ah} \\
\text { (Meulen et al., } \\
2015 \text { ) } \\
1.4 \mathrm{MBq} / \mu \mathrm{Ah} \\
\text { (Hoehr et al., } \\
\text { 2014) }\end{array}$ \\
\hline
\end{tabular}




\section{Conclusions}

This review presented the developments in small medical cyclotron production of radionuclides used for diagnostics over the past few years (Table 4). Some are increasingly being used in nuclear medicine, i.e. ${ }^{68} \mathrm{Ga}$ and ${ }^{89} \mathrm{Zr}$. Some have a fast clinical introduction, taking over the field already occupied by previously implemented methods such as: cyclotron produced ${ }^{99 \mathrm{~m}} \mathrm{Tc}$ over previous molybdenum generator supplied ${ }^{99 \mathrm{~m}} \mathrm{Tc} ;{ }^{89} \mathrm{Zr}$ over ${ }^{64} \mathrm{Cu}$ in antibody labeling mostly due to a better suited half-life and no enrichment. And lastly, some novel radionuclides, like ${ }^{86} \mathrm{Y}$ or ${ }^{44} \mathrm{Sc}$, present promising data for production implementation using SMCs, while gaining interest in clinical applications.

Certainly, there are still many concerns for commercializing these novel cyclotron produced radionuclides. Apart from regulatory, financial, pharmaceutical and chemical concerns, there are also technical concerns. These include low production yields, costs of enriched materials, and improvement of solid target methodology, which is time consuming. In our opinion, more work should be published that encompasses production and optimization of non-standard radionuclides using standardized types of compact solid target systems per specific radionuclide. We would like to encourage the commercial compact solid target system users to share their production results and parameters. An alternative method employs the use of liquid targets for this purpose. A number of studies were reported in this paper on the production of novel radionuclides using liquid targets, but so far, the yields reached were mostly too low for commercial implementation. Addressing this issue still requires extensive research in the field of liquid targets used for the production of novel radionuclides.

\section{Abbreviations}

ACSI: Advanced Cyclotron Systems Incorporated; COSTIS: Compact Solid Target Irradiation System; EOB: End of bombardment; GE Healtcare: General Electric Healthcare; GMP: Good manufacturing practice; HEU: Highly enriched uranium; IAEA: International Atomic Energy Agency; IBA: Ion Beam Applications; ICAN: International Coherent Amplification Network; J-PARC: Japan Proton Accelerator Research Complex; LINAC: Linear accelerator; mAbs: Monocolonal antibodies; MURR: University of Missouri Research Reactor Center; PET: Positron emission tomography; SMC: Small medical cyclotron; SPECT: Single photon emission computed tomography; VU: Vrije Universiteit Amsterdam

Acknowledgements

We would like to thank Roel Mooij, Chief engineer and Manager R\&D Cyclotron and Targetry from BV Cyclotron VU for providing us materials about custom made solid targetry for Zirconium-89 production.

Funding

No funding received

\section{Availability of data and materials}

The dataset(s) supporting the conclusions of this article is(are) available in the IAEA - Nuclear Data Section Live Chart of Nuclides repository: https://www-nds.iaea.org/relnsd/vcharthtml/VChartHTML.html

\section{Authors' contributions}

Substantial contributions to the conception or design of the work: MAS, LRP, JFWN, Acquisition of data: MAS, LRP, Analysis and interpretation of data for the work: MAS, LRP, JFWN, Drafting of the work: MAS, Critical revision of the work for important intellectual content: LRP, JFWN, Final approval of the version to be published: MAS, LRP, JFWN, Agreement to be accountable for all aspects of the work in ensuring that questions related to the accuracy or integrity of any part of the work are appropriately investigated and resolved: MAS, LRP, JFWN. All authors read and approved the final manuscript.

Ethics approval and consent to participate

Not applicable 


\section{Competing interests}

J.F.W. Nijsen is co-founder and chief scientific officer (0.5 FTE) of Quirem Medical BV. He owns shares in the company Quirem Medical BV and holds several patents on his name as inventor.

\section{Publisher's Note}

Springer Nature remains neutral with regard to jurisdictional claims in published maps and institutional affiliations.

\section{Author details}

${ }^{1}$ Radboudumc, Radboud Translational Medicine B.V, Geert Grooteplein 21 (route 142), 6525EZ Nijmegen, The Netherlands. ${ }^{2}$ Radboudumc, Dept. of Radiology and Nuclear Medicine, Geert Grooteplein-Zuid 10, 6525GA Nijmegen, The Netherlands.

Received: 1 November 2017 Accepted: 24 January 2018

Published online: 20 February 2018

\section{References}

Accelerator-based Alternatives to Non-HEU production of Mo-99/Tc-99m 2011; IAEA coordinated research project]. Available from: http://cra.iaea.org/crp/project/ProjectDetail?projectld=1862\&lastActionName=OpenedCRPList.

ACSI. CycloTec ${ }^{\mathrm{TM}}$ and the National Cyclotron Network: meeting Canada's medical isotope needs. Available from: http:// www.advancedcyclotron.com/sites/default/files/cyclotec_and_the_national_cyclotron_network.pdf.

Alfuraih A, et al. Optimization of Zr-89 production using Monte Carlo simulations. J Radioanalytical Nucl Chem. 2013; 296(2):1025-9.

Alipoor Z, Gholamzadeh Z, Sadeghi M. Data evaluation acquired Talys 1.0 code to produce in-111 from various accelerator-based reactions. Int J Mod Phys E Nucl Phys. 2011;20(5):1307-24.

Alliot $C$, et al. Cyclotron production of high purity $(44 \mathrm{~m}, 44)$ sc with deuterons from $(44) \mathrm{CaCO} 3$ targets. Nucl Med Biol. 2015;42(6):524-9.

Alves F, et al. Production of copper-64 and gallium-68 with a medical cyclotron using liquid targets. Mod Phys Lett A. 2017;32(17):21.

Al-Yanbawi S, Al Jammaz I. Standardized high current solid tellurium-124 target for cyclotron production of the radionuclides iodine-123,124. Radiochim Acta. 2007;95(11):657-61.

Applications, A.A., Advanced accelerator applications announces European Commission approval of SomaKit TOC ${ }^{\mathrm{TM}}$. 2016.

Asad $\mathrm{AH}$, et al. Excitation functions of natZn $(p, x)$ nuclear reactions with proton beam energy below $18 \mathrm{MeV}$. Appl Radiat Isot. 2014;94:67-71.

Aslam MN, Amjed N, Qaim SM. Evaluation of excitation functions of the 68,67,66Zn (p,xn)68,67,66Ga and 67Zn $(p, a) 64 C u$ reactions: validation of evaluated data through comparison with experimental excitation functions of the natZn (p,x)66,67Ga and natZn (p,x)64Cu processes. Appl Radiat Isot. 2015;96:102-13.

Aslam MN, et al. Evaluation of excitation functions of proton and deuteron induced reactions on enriched tellurium isotopes with special relevance to the production of iodine-124. Appl Radiat Isot. 2010;68(9):1760-73.

Avila-Rodriguez MA, Nye JA, Nickles RJ. Simultaneous production of high specific activity 64Cu and 61Co with $11.4 \mathrm{MeV}$ protons on enriched 64Ni nuclei. Appl Radiat Isot. 2007;65(10):1115-20.

Avila-Rodriguez MA, Nye JA, Nickles RJ. Production and separation of non-carrier-added $86 \mathrm{Y}$ from enriched $86 \mathrm{Sr}$ targets. Appl Radiat Isot. 2008:66(1):9-13.

Azizakram H, et al. An overview of I-124 production at a medical cyclotron by ALICE/ASH, EMPIRE-3.2.2 and TALYS-1.6 codes. Appl Radiat Isot. 2016;112:147-55.

Bach HT, et al. Improving the survivability of Nb-encapsulated Ga targets for the production of Ge-68. Nucl Inst Methods Phys Res Sec B Beam Interact Mater Atoms. 2013;299:32-41.

Beaver JE, Hupf HB. Production of Tc-99m on a medical cyclotron - feasibility study. J Nucl Med. 1971;(11):12, 739

Benard F, et al. Implementation of multi-curie production of Tc-99m by conventional medical cyclotrons. J Nucl Med. 2014:55(6):1017-22.

Blaauw M, et al. Estimation of 99Mo production rates from natural molybdenum in research reactors. J Radioanalytical Nucl Chem. 2017:311(1):409-18.

Braghirolli AMS, et al. Production of iodine-124 and its applications in nuclear medicine. Appl Radiat Isot. 2014;90:138-48.

Brief, A.R.S.N., FDA approves first gallium 68Ga-Dotatate radiopharmaceutical tracer for PET imaging of neuroendocrine tumors. 2016

Brown, C. Will new isotope sources be ready in time? CMAJ : Can Med Assoc J 2016 ; [252-252]. Available from: http:// www.ncbi.nlm.nih.gov/pmc/articles/PMC4771533/. [Cited 188 4].

Buckley K. Cyclotron production of Tc-99m. Cyclotrons2013. Proc 20th Int Conf Cyclotrons Appl. 2013:482-6.

Bychenkov VY, Brantov AV, Mourou G. Tc-99m production with ultrashort intense laser pulses. Laser and Particle Beams. 2014;32(4):605-11.

Cwikla JB, et al. 67Ga SPECT in detection of infection and inflammation. Nucl Med Rev Cent East Eur. 1999:2(2):69-73.

Dabkowski AM, et al. Optimization of cyclotron production for Radiometal of zirconium 89. Acta Phys Pol A. 2015; 127(5):1479-82.

Das MK, et al. Production and separation of Tc-99m from cyclotron irradiated mo-100/natural targets: a new automated module for separation of Tc-99m from molybdenum targets. J Radioanalytical Nucl Chem. 2016;310(1):423-32.

DeGrado TR, Pandey MK, Byrne J. Solution target for cyclotron production of radiometals: Google Patents; 2017.

Ellison PA, et al. Spot-welding solid targets for high current cyclotron irradiation. Appl Radiat Isot. 2016;118:350-3.

Engle JW, et al. Very high specific activity Ga-66/68 from zinc targets for PET. Appl Radiat Isot. 2012;70(8):1792-6. 
Filosofov DV, Loktionova NS, Rösch F. A 44Ti/44Sc radionuclide generator for potential application of 44Sc-based PET-radiopharmaceuticals: Radiochimica Acta International journal for chemical aspects of nuclear science and technology; 2010. p. 149.

Fitzsimmons JM, Mausner L. Production scale purification of Ge-68 and Zn-65 from irradiated gallium metal. Appl Radiat Isot. 2015a;101:60-4.

Fitzsimmons JM, Mausner L. Development of a production scale purification of Ge-68 from irradiated gallium metal. Radiochim Acta. 2015b;103(2):117-23.

Fonslet J, Koziorowski J. Dry distillation of radioiodine from TeO2 targets. Appl Sci Basel. 2013;3(4):675-83.

Fujiwara M, et al. Production of medical (99m) Tc isotope via photonuclear reaction. Phys Part Nuclei. 2017;48(1):124-33.

Goethals PE, Zimmermann RG. Cyclotrons used in Nuclear Medicine World Market Report \& Directory. 2015th ed; 2015.

Hanemaayer V, et al. Solid targets for Tc-99m production on medical cyclotrons. J Radioanalytical Nucl Chem. 2014; 299(2):1007-11.

Harvey JT, Isensee GH, Moffatt SD, Messina GP. NorthStar progress towards domestic Mo99 production. Washington, DC: presented at Topical Meeting on Molybdenum-99 Technological Development, June 2014; 2014.

Hernandez R, et al. Sc-44: an attractive isotope for peptide-based PET imaging. Mol Pharma. 2014;11(8):2954-61.

Hoehr C, et al. Radiometals from liquid targets: $94 \mathrm{mTC}$ production using a standard water target on a $13 \mathrm{MeV}$ cyclotron. Appl Radiat Isot. 2012;70(10):2308-12.

Hoehr C, et al. (SC)-S-44g production using a water target on a $13 \mathrm{MeV}$ cyclotron. Nuc Med Biol. 2014;41(5):401-6.

Holland JP, Sheh YC, Lewis JS. Standardized methods for the production of high specific-activity zirconium-89. Nuc Med Biol. 2009;36(7):729-39.

Huclier-Markai $\mathrm{S}$, et al. Optimization of reaction conditions for the radiolabeling of DOTA and DOTA-peptide with $44 \mathrm{~m} / 44 \mathrm{Sc}$ and experimental evidence of the feasibility of an in vivo PET generator. Nucl Med Biol. 2014;41:e36-43.

IAEA. Production of long lived parent Radionuclides for generators: 68Ge, 82Sr, 90Sr and 188W, in IAEA radioisotopes and radiopharmaceuticals series. Vienna: International Atomic Energy Agency; 2010.

IAEA, Cyclotron Produced Radionuclides: Principles and Practice. Technical report series no.465. Vienna: International Atomic Energy Agency; 2008

Ikotun OF, Lapi SE. The rise of metal radionuclides in medical imaging: copper-64, zirconium-89 and yttrium-86. Future Med Chem. 2011;3(5):599-621.

Jalilian AR. An overview on Ga-68 radiopharmaceuticals for positron emission tomography applications. Iran J Nuc Med. 2016;24(1):1-10.

Jalilian AR, Osso J. The current status and future of theranostic Copper-64 radiopharmaceuticals. Iran J Nucl Med. 2017; 25(1):1-10.

Jalilian AR, et al. Evaluation of [67Ga] citrate in the detection of various microorganism infections in animal models. Iran J Nucl Medi. 2009:17(2):34-41.

Jones SC, Robinson GD Jr, McIntyre E. Tandem van de Graaff accelerator production of positron labeled radiopharmaceuticals for routine clinical use. Int J Appl Radiat Isot. 1984;35(8):721-9.

Kakavand T, et al. Computer simulation techniques to design Xenon-124 solid target for iodine-123 production. Iran J Radiat Res. 2008;5(4):207-11.

Kalsy N, Vinjamuri S. Should we stop offering indium-111 octreotide scans in favour of gallium-68 PET-CT scans in the UK? Nucl Med Commun. 2016;37(12):1221-2.

Koehler L, et al. lodine-124: a promising positron emitter for organic PET chemistry. Molecules. 2010;15(4):2686-718

Krajewski S, et al. Cyclotron production of sc-44 for clinical application. Radiochim Acta. 2013;101(5):333-8.

Krijger GC, et al. The necessity of nuclear reactors for targeted radionuclide therapies. Trends Biotechnol. 2013;31(7):390-6.

Lahiri S, Maiti M, Ghosh K. Production and separation of in-111: an important radionuclide in life sciences: a mini review. J Radioanalytical Nucl Chem. 2013;297(3):309-18

Lighthouse: productie medische isotopen vanaf 2021. 2017; Available from: https://www.laka.org/nieuws/2017/lighthouseproductie-medische-isotopen-vanaf-2021-6663.

Mahunka I, et al. Iodine-123 production at a small cyclotron for medical use. J Radioanalytical Nucl Chem Lett. 1996;213(2):135-42.

Manenti S, et al. The excitation functions of mo-100(p,x) mo-99 and mo-100(p,2n) Tc-99m. Appl Radiat Isot. 2014;94:344-8.

Mang'era K, et al. Processing and evaluation of linear accelerator-produced mo-99/Tc-99m in Canada. J Radioanalytical Nucl Chem. 2015;305(1):79-85.

Martins PD, Osso JA. Thermal diffusion of Ga-67 from irradiated Zn targets. Appl Radiat Isot. 2013;82:279-82.

Matarrese $\mathrm{M}$, et al. Automated production of copper radioisotopes and preparation of high specific activity [64Cu]cuATSM for PET studies. Appl Radiat Isot. 2010;68(1):5-13.

Meulen NPvd, et al. Cyclotron production of ${ }^{44}$ Sc: from bench to bedside. Nulc Med Biol. 2015;42:745-51.

Nagatsu K, et al. Fully automated production of iodine-124 using a vertical beam. Appl Radiat Isot. 2011;69(1):146-57.

Nakai K, et al. Feasibility studies towards future self-sufficient supply of the $<$ sup $>99</$ sup $>$ mo- $<$ sup $>99 m</$ sup $>T C$ isotopes with Japanese accelerators. Proc Japan Acad Ser B. 2014;90(10):413-21.

NorthStar Medical Radioisotopes Receives \$11.75 Million from National Nuclear Security Administration. 2015; Available from: https://www.northstarnm.com/newsroom/.

OECD-NEA. 2017 medical isotope supply review: 99Mo/99mTc market demand and production capacity projection 2017-2022: The Supply of Medical Radioisotopes; 2017.

Oehlke $\mathrm{E}$, et al. Production of $\mathrm{Y}-86$ and other radiometals for research purposes using a solution target system. Nucl Med Biol. 2015;42(11):842-9.

Ohya T, et al. Efficient preparation of high-quality 64Cu for routine use. Nucl Med Biol. 2016;43(11):685-91.

Pandey M, et al. Cyclotron production of Ga-68 using a solution target. J Nucl Med. 2014a;55:1.

Pandey MK, et al. Cyclotron production of (68) Ga via the $(68) \mathrm{Zn}(\mathrm{p}, \mathrm{n})(68) \mathrm{Ga}$ reaction in aqueous solution. Am J Nucl Med Mol Imaging. 2014b;4(4):303-10.

Pandey MK, et al. Improved production and processing of Zr-89 using a solution target. Nucl Med Biol. 2016:43(1):97-100.

Park HM. I-123: almost a designer radioiodine for thyroid scanning. J Nucl Med. 2002;43(1):77-8. 
Poniger SS, et al. Automated production of 124 and 64Cu using IBA Terimo and Pinctada metal electroplating and processing modules. AlP Conf Proc. 2012;1509(1):114-9.

Pupillo G, et al. Accelerator-based production of mo-99: a comparison between the mo-100(p,x) and Zr-96(alpha,n) reactions. J Radioanalytical Nucl Chem. 2015;305(1):73-8.

Qaim SM. The present and future of medical radionuclide production: Radiochimica Acta; 2012. p. 635.

Qaim SM. Nuclear data for production and medical application of radionuclides: present status and future needs. Nucl Med B. 2017:44:31-49.

Qaim SM, et al. Some optimisation studies relevant to the production of high-purity $124 \mathrm{l}$ and $120 \mathrm{gl}$ at a small-sized cyclotron. Appl Radiat Isot. 2003;58(1):69-78.

Qaim SM, et al. Evaluation of excitation functions of mo-100(p,d+pn) mo-99 and mo-100 (p,2n) Tc-99m reactions: estimation of long-lived Tc-impurity and its implication on the specific activity of cyclotron-produced Tc-99m. App Radiat Isot. 2014;85:101-13.

Qaim Syed M. Development of novel positron emitters for medical applications: nuclear and radiochemical aspects: Radiochimica Acta International journal for chemical aspects of nuclear science and technology; 2011. p. 611.

Rajec P, et al. Preparation and characterization of nickel targets for cyclotron production of $64 \mathrm{Cu}$. J Radioanalytical Nucl Chem. 2010;286(3):665-70.

Reischl G, Roesch F, Machulla H-J. Electrochemical separation and purification of yttrium-86. 2002;90:225-8.

Rice $S L$, et al. The next generation of positron emission tomography radiopharmaceuticals in oncology. Semin Nucl Med. 2011;41(4):265-82.

Roesch F. Maturation of a key resource - the germanium-68/gallium-68 generator: development and new insights. Curr Radiopharm. 2012a;5(3):202-11.

Roesch F. Scandium-44: benefits of a long-lived PET radionuclide available from the (44) Ti/(44) sc generator system. Curr Radiopharm. 2012b;5(3):187-201.

Rösch F, Herzog H, Qaim SM. The beginning and development of the Theranostic approach in nuclear medicine, as exemplified by the radionuclide pair (86) Y and (90) Y. Pharmaceuticals. 2017;10(2):56.

Rovais MRA, et al. Assessment of the direct cyclotron production of Tc-99m: an approach to crisis management of TC-99m shortage. Appl Radiat Isot. 2016;112:55-61.

Sadeghi M, Enferadi M, Bakhtiari M. Accelerator production of the positron emitter zirconium-89. Ann Nucl Energy. 2012;41:97-103.

Schaffer $P$, et al. Direct production of 99mTc via 100Mo (p,2n) on small medical cyclotrons. Phys Procedia. 2015;66:383-95.

Schmor, P.W. Review of cyclotrons used in the production of radioisotopes for biomedical applications. in Proceedings of Cyclotrons 2010. 2010. Lanzhou.

Siikanen J, et al. A solid target system with remote handling of irradiated targets for PET cyclotrons. Appl Radiat Isot. 2014;94:294-301.

Silberstein EB. Radioiodine: the classic Theranostic agent. Semin Nucl Med. 2012;42(3):164-70.

Soppera NDE, Bossant M, Cabellos O. JANIS book of proton induced cross sections, comparison of evaluated and experimental data from ENDF/B-VII.1, JENDL/HE-2007, PADF-2007, TENDL-2015 and EXFOR: OECD NEA Data Bank; 2017a.

Soppera NDE, Bossant M, Cabellos O. JANIS book of deuteron induced cross sections: Comparison of evaluated and experimental data from ENDF/B-VII.1, TENDL-2015 and EXFOR; 2017b.

Sounalet T, et al. Strontium-82 and future Germanium-68 production at the ARRONAX facility. Nuclear Data Sheets. 2014;119:261-6.

Stolarz A, et al. Molybdenum targets produced by mechanical reshaping. J Radioanalytical Nucl Chem. 2015;305(3):947-52.

Szelecsényi F, Blessing G, Qaim SM. Excitation functions of proton induced nuclear reactions on enriched 61Ni and 64Ni: possibility of production of no-carrier-added 61Cu and 64Cu at a small cyclotron. Appl Radiat Isot. 1993;44(3): 575-80.

Szelecsényi $F$, et al. Excitation function of $(p, a)$ nuclear reaction on enriched 67Zn: possibility of production of 64Cu at Iow energy cyclotron: Radiochimica Acta; 2014. p. 465.

Szkliniarz K, et al. Production of medical sc radioisotopes with an alpha particle beam. Appl Radiat Isot. 2016;1 18:182-9.

Takacs S, et al. Benchmark experiment for the cross section of the mo-100(p,2n) Tc-99m and mo-100(p,pn) mo-99 reactions. Nucl Instrums Methods Phys Res Sec B Beam Interact Mater Atoms. 2016;375:60-6.

Tang Y, et al. A simple and convenient method for production of Zr-89 with high purity. Appl Radiat Isot. 2016;118: 326-30.

Tárkányi F, et al. Excitation functions of deuteron induced nuclear reactions on natural zinc up to $50 \mathrm{MeV}$. Nucl Inst Methods Phys Res Sec B Beam Interact Mater Atoms. 2004;217(4):531-50.

Valdovinos HF, et al. Separation of cyclotron-produced sc-44 from a natural calcium target using a dipentyl pentylphosphonate functionalized extraction resin. Appl Radiat Isot. 2015;95:23-9.

van der Marck SC, Koning AJ, Charlton KE. The options for the future production of the medical isotope 99Mo. Eur J Nucl Med Mol Imaging. 2010;37(10):1817-20.

Vosjan MJWD, et al. Conjugation and radiolabeling of monoclonal antibodies with zirconium-89 for PET imaging using the bifunctional chelate p-isothiocyanatobenzyl-desferrioxamine. Nat Protocols. 2010;5(4):739-43.

Yoo J, et al. Preparation of high specific activity 86Y using a small biomedical cyclotron. Nucl Med Biol. 2005;32(8):891-7.

Zaneb H, et al. Nuclear model analysis of excitation functions of proton induced reactions on Sr-86, Sr-88 and Zr-nat: evaluation of production routes of Y-86. Appl Radiat Isot. 2015;104:232-41.

Zimmermann RG. Why are investors not interested in my radiotracer? The industrial and regulatory constraints in the development of radiopharmaceuticals. Nucl Med Biol. 2013;40(2):155-66. 